NBER WORKING PAPER SERIES

\title{
PREMIUM OR PENALTY? LABOR MARKET RETURNS TO NOVICE PUBLIC SECTOR TEACHERS
}

\author{
Juan Saavedra \\ Dario Maldonado \\ Lucrecia Santibanez \\ Luis Omar Herrera Prada \\ Working Paper 24012 \\ http://www.nber.org/papers/w24012
}

\author{
NATIONAL BUREAU OF ECONOMIC RESEARCH \\ 1050 Massachusetts Avenue \\ Cambridge, MA 02138 \\ November 2017
}

We acknowledge funding from the Inter American Development Bank (IADB). We thank Mariana Alfonso, Ivan Enríquez, Carlos Hipólito García, Abhijit Singh, Nadmy Valbuena, and participants at AEFP Conference 2017, NBER, the CESIfo Economics of Education Conference 2016, LACEA-LAMES Conference 2016 and in the Colombian Ministry of Education, UCLA, USC, MSU Universidad EAFIT and Universidad de la Salle's seminars for helpful comments and suggestions. Olga Victoria Dulce at Universidad de los Andes provided excellent research assistance in Colombia. We thank Dolly Ovalle and Luz Emilse Rincón at Colombia's Ministry of Social Protection for providing access to social security employment and earnings data. Colombia's Ministry of Education provided access to teacher rosters. All remaining errors are our own. The views expressed herein are those of the authors and do not necessarily reflect the views of the National Bureau of Economic Research.

NBER working papers are circulated for discussion and comment purposes. They have not been peer-reviewed or been subject to the review by the NBER Board of Directors that accompanies official NBER publications.

(C) 2017 by Juan Saavedra, Dario Maldonado, Lucrecia Santibanez, and Luis Omar Herrera Prada. All rights reserved. Short sections of text, not to exceed two paragraphs, may be quoted without explicit permission provided that full credit, including $\odot$ notice, is given to the source. 
Premium or Penalty? Labor Market Returns to Novice Public Sector Teachers

Juan Saavedra, Dario Maldonado, Lucrecia Santibanez, and Luis Omar Herrera Prada

NBER Working Paper No. 24012

November 2017

JEL No. I26,J22,J24,O15,O38

\begin{abstract}
$\underline{\text { ABSTRACT }}$
It is unclear whether public sector teachers are under or overpaid relative to other occupations due to lack of knowledge about teachers' outside labor market options and other unobserved attributes related to compensation. We estimate causal labor market returns to novice public teachers in Colombia. Our approach takes advantage of a national, standardized, teacher-screening exam, scores on which determine eligibility for public teaching jobs. We use four nationwide administrative data sources in a regression discontinuity approach to show that applicants who marginally pass the teacher screening test have greater annual earnings during the first three years of tenure than applicants below the passing cutoff. The total earnings effect is a combination of higher daily wages and greater labor supply, part of which is in outside, predominantly nonteaching jobs for a substantial fraction of public teachers. For infra-marginal high-scoring applicants, we show that being a public teacher in Colombia is as attractive, if not more, as for those at the margin. On the whole, rather than a penalty, public teachers in Colombia across all ability levels earn a substantial labor market premium early in their careers.
\end{abstract}

Juan Saavedra

Dornsife Center for Economic and Social Research University of Southern California

635 Downey Way

Los Angeles, CA 90089

and NBER

juansaav@usc.edu

Dario Maldonado

Cr 1 No 19-27

Bloque AU, piso 2 Ofc: 220

Bogota, Colombia

dmaldonadoc@uniandes.edu.co
Lucrecia Santibanez

School of Educational Studies

Claremont Graduate University

Harper Hall 205150 East Tenth St.,

Claremont California 91711

Lucrecia.Santibanez@cgu.edu

Luis Omar Herrera Prada

The World Bank

1818 H Street, NW

Washington, DC 20433

luis.o.herrera@me.com 


\section{Introduction}

In an effort to raise educational quality, countries around the world grapple with the question of how to attract top talent into the teaching profession. Initiatives often target teacher compensation, arguing that public teachers are underpaid relative to similarly qualified professionals in other occupations (e.g. Auguste, Kim and Miller, 2010; Mizala and Ñopo, 2016). It is unclear, however, whether public sector teachers are under or overpaid, because we generally lack knowledge on teachers' outside labor market options, cognitive ability, and other unobserved attributes related to compensation.

In this paper we estimate causal labor market returns to novice public sector teachers in Colombia. For mainly two reasons, Colombia provides an exceptional setting to address this question. First, for recent applicants, the Colombian government allocates public teaching jobs using scores on a national, standardized, teacher-screening exam, which provides exogenous variation in the probability of becoming a public sector teacher among ap-

plicants with marginal scores. Second, rich Colombian administrative data sources enable us to create a new individual-level longitudinal dataset containing information for all prospective teachers on their secondary graduation exam and collegiate records, performance on the teacher screening test, and labor market history two years prior and three years after they take the screening test. These data, in particular, enable us to observe labor market outcomes for public teachers in their public sector teaching job as well as in any additional jobs they hold.

Theoretically, if the test has screening value and is costly, it creates 
an entry-barrier effect that unambiguously results in higher average teacher wages (Angrist and Guryan, 2007). It is theoretically ambiguous, however, the extent to which the labor market returns to marginal applicants are positive or negative and the extent to which we can extrapolate such causal returns to infra-marginal applicants who score high on the screening test.

Empirically we find that public sector teachers in Colombia earn a substantial earnings premium early in their careers. Applicants who marginally pass the teacher screening test have annual earnings that are about 65 percent greater during the first three years of tenure than earnings of applicants just below the cutoff. Part of the premium is due to the fact that a significant fraction of public sector teachers hold outside, predominantly non-teaching jobs in the formal sector. As a result, relative to applicants who fail, applicants who pass the teacher screening test work more days per year and have higher daily earnings. However, the earnings advantage from the second job wanes after two years and by the third year of potential teacher tenure, most of the earnings premium for marginal applicants is due entirely to their primary public teaching job.

To address the question of whether public teaching jobs are as attractive for infra-marginal high scoring applicants as they are for marginal applicants near the cutoff, we take advantage of the fact that conditioning on the large set of baseline predictors in our data effectively eliminates the relationship between teacher screening test scores as the running variable and applicants' potential labor market earnings, thereby eliminating the only source of omitted variables bias in discontinuity-based estimates (Angrist and Rokkanen, 2015). A propensity score stratification strategy based on this ignorability 
result suggests that, in both the main occupation and for all occupations, the labor market premium for infra-marginal high-scoring public teachers is greater than for teachers with marginal scores.

While it is difficult to conclude with our available data whether the substantial premium earned by Colombian public teachers early in their careers results in a better pool of teachers, some evidence suggests that it may not. First, to the extent that the test is costly, some applicants will be discouraged from taking it. Therefore, applicants on the margin between public teaching and an alternative occupation should be the highest-quality teachers (Angrist and Guryan, 2007). Consistent with this theoretical prediction, we find that relative to recent college graduates who take the teacher screening test, those who choose not to take it have higher college admission exam scores and come from more socio-economically advantageous backgrounds, both of which are strong predictors of student achievement and of teacher value-added in the US (Clotfelter, Ladd and Vigdor, 2010).

Second, economic theory highlights how effort depends on marginal incentives (e.g. Holmstrom and Milgrom 1991; Holmstrom 1999). After a short probationary period, usually 6 months, most novice teachers in Colombia receive tenure and are rarely dismissed. Teacher salaries are set using a seniority and education-based salary schedule, and are untied to performance. The work conditions of public teachers make it plausible that, on the margin, they will devote more effort to their outside, less secure, non-teaching job, possibly at the expense of teaching.

Third, evidence from other developing countries indicates considerable misallocation of pay and productivity among public workers in general and 
teachers in particular. In Mexico, for instance, recent evidence shows that raising public sector salaries improved applicant pool quality and motivation but not necessarily job performance (Dal Bo et al, 2013). In Pakistan, reducing teacher pay by 35 percent had no adverse effect on teacher productivity, as measured by test-score value added (Bau and Das, 2016). In Indonesia, doubling teacher pay reduced the fraction of teachers holding outside jobs, but did not affect teacher effort or student performance (de Ree et al., 2015) $!^{1}$

The rest of the paper proceeds as follows. Section 2 describes the structure of public teacher hiring in Colombia and the teacher screening test reform introduced in 2004. Sections 3 and 4 describe the data and research design. Section 5 presents our main findings. Section 6 discusses findings from an analysis that extrapolates our results to candidates away from the cutoff. Section 7 concludes.

\section{Public teacher hiring in Colombia}

Evidence suggests that it is difficult to identify effective teachers at the point of hire: observable characteristics such as educational background are poor predictors of performance on the job (Rockoff, Jacob, Kane, and Staiger, 2011).

To improve the quality of the teaching force, countries around the world have introduced licensure requirements for prospective teachers. In England, for example, prospective teachers must pass the Teacher Training Agency

\footnotetext{
${ }^{1}$ In England, on the other hand, recent evidence suggests that regions in which teachers earn poorly relative to other occupations have lower student achievement than regions in which teachers earn on par with other occupations (Britton and Propper, 2016).
} 
skills test to become public sector teachers (Wang et al., 2003). In the US, more than 40 states require teachers to pass some sort of standardized certification test (Angrist and Guryan, 2007). Mexico and Peru use a national test to screen all potential new teachers, similar to the one we use in this study (Estrada, 2013).

In 2002, the Colombian government modified the conditions that determine entry into the public teaching profession. This reform was undertaken with the goal of raising entry standards for public sector teaching and making the selection process more transparent and meritocratic. The new selection rules went into effect in 2004 and only apply to applicants who wish to become public teachers.

Colombia's Civil Service Commission manages the new recruitment process ${ }^{2}$ The new recruitment process consists of three stages. In the first stage, aspiring teachers take a screening test; eligibility depends on the result of the test. To take the test applicants must pay a fee; in 2009, it was 25,000 Colombian pesos, or about US $\$ 13$. Only applicants with scores on the screening test at or above 60 points are eligible for public sector teaching jobs. The 60-point cutoff is fixed ex-ante by the Ministry of Education.

The teacher screening test assesses applicants' cognitive ability (mathematics, language and pedagogy), content knowledge (specific to the subject matter the person wants to teach), and personality traits. The test has substantial power as a quality screen. In 2009 - the test cohort we study - only 42 percent of applicants passed the test. Moreover, the probability of pass-

\footnotetext{
${ }^{2}$ The Commission also manages recruitment and promotions for most other civil servants with the exception of military and police forces.
} 
ing the test is correlated with applicants' outside options. Among recent education college graduates who take the 2009 screening test, scores on the test are positively correlated with earnings in the prior year.

In the second stage of the teacher selection process, officials from the National Public Service Commission interview applicants with scores above the eligibility cutoff to verify applicant qualifications and degrees. At this second stage the government disqualifies applicants who lack any pre-requisites, such as having a Bachelor's degree. Once the commission has determined the pool of all eligible applicants, it generates a list ranking candidates by test results. These rankings are generated one for each "Departamento" or state in Colombia and for all large cities $3^{3}$

In the third stage, applicants choose their preferred vacancy. Selection follows rank order: applicants with higher scores can choose vacancies first, until all public sector teacher vacancies are assigned. Since the reform was enacted there have been five teacher screening test administrations: 2004, 2005, 2006, 2009, 2013, 2015, and 2017. Owing data restrictions that are explained in detail below, we focus on graduates who took the 2009 test. The teacher screening test, as we show later in the paper, creates plausibly exogenous variation in the probability of obtaining a permanent public sector teaching position around the eligibility threshold.

\footnotetext{
${ }^{3}$ Teachers apply to take the test in their preferred state or geographic location. Colombia is divided into 32 "Departamentos" or states plus the capital city of Bogotá. The Ministry of Education constructs local ranking lists by state and one for the capital district, so that teachers can be assigned locally within these regions.
} 


\section{Data and Methods}

\subsection{Data}

Our dataset combines information from four administrative sources. These sources are merged using national identification information on names, dates of birth and adult identification (ID) numbers:

1. Teacher screening test data for the 2009 application cohort. These data contain individual-results for all applicants who took the test in 2009. We obtained these data from Colombia's National Educational Assessment Agency (ICFES). Because available earnings data begin in 2008 (see below), we limit our sample to applicants who took the teacher screening test in 2009 so that we can observe at least one year of pre-test labor market outcomes.

2. Colombian Tertiary Education Database (SPADIES) for college graduating cohorts 2007-2009. This dataset contains individual-level information on key baseline covariates such as secondary graduation exam scores, demographics, freshman and graduation year, whether the individual received financial aid during college, and the university and program from which each individual graduated, which allows to construct measures of college quality based on mean entry scores of graduates. Our main sample consist of all graduates from all knowledge areas from 2007 to 2009 (313,066 graduates). In our main analytic sample, we restric to those who took the screening test in 2009 (31,699 applicants). 
3. Public sector teacher payroll data, 2008-2012. Using these data we can identify which graduates hold permanent positions as public sector teachers, the region in which they work and their public teacher pay schedule.

4. National Social Security earnings records for all college's graduates from 2008 to 2012. Includes data on all formal sector employees in the country, including monthly wages, employment intensity (days worked in the formal sector per year) and occupational codes. Importantly, the social security earnings records do not cover public sector teachers (or military officers) since these sectors have separate pension regimes. Therefore, to the extent that public sector teachers appear in the national social security records it implies that they hold another formal sector job outside public teaching. This is something we investigate in detail in our empirical analyses. Because our teacher payroll and social security data span until 2012, we can observe labor market outcomes for up to three years after an individual took the 2009 teacher-screening test.

Table 1 shows mean comparisons of college graduates from graduating cohorts 2007-2009 who took the 2009 test and of those who did not. Note that in Colombia, any college graduate can take the teacher entry exam, not just education majors. Moreover, not all education graduates choose to take the public teacher screening test and among education graduates in graduating cohorts 2007-2009 about 60 percent take the screening test. In our empirical analyses we take advantage of this fact to investigate differences in the 
labor market returns for for education and non-education majors who wish to become public teachers.

[Table 1 about here.]

Consistent with the "discouragement" hypothesis of a costly screening test (e.g. Angrist and Guryan 2007) non-test takers are potentially more effective teachers to the extent that they are more likely to come from socioeconomically advantaged households (as measured by income and the probability of having a mother with a college degree), have higher secondary graduation exam scores - in Colombia these scores are the main college admission criterion,- - and graduate from better colleges (as measured by the proportion who graduate from an accredited higher education institution). Relative to non-test takers, test takers are also more likely to be female. Among those who took the test, we have complete covariate and outcome information for 88 percent $(31,699$ graduates $) 4^{4}$ Teachers can take the test several times, and exam repetition may raise concerns for test-score manipulation. While we show balance just above and just below the cutoff in covariates and density, we repeat all estimations without exam repeaters; our main findings remain unchanged.

Formal labor force attachment is high in the study's population (Table 2). In the two years of pre-exam labor market data we have (2008 and 2009) over 45 percent of 2009 test takers-many of whom are still enrolled in tertiary education- worked in the formal sector, as measured by being matched to social security records. Over time, the fraction of test-takers with formal

\footnotetext{
${ }^{4}$ Of these, about 31 percent (9,874 graduates) also took the exam in at least one of the prior administrations (2004, 2005 or 2006).
} 
sector attachment diminishes as a higher fraction of eligible test-takers enter public sector teaching (column 2, Table 2). Combining public teacher payroll data and social security data allows us to have a broader perspective on the labor market outcomes of applicants, among whom close to 73 percent appear in either teacher payroll or social security records (column 4, Table 2). A non-trivial percent of the sample - ranging from 4 to 8 percent in the years after the test (2010-2012) — appears in both teacher payroll and social security data-implying that in addition to being public sector teachers, these applicants also hold another formal sector job (column 5, Table 2). As a fraction of public sector teachers with permanent positions (column 2, Table 2), those who also hold outside formal jobs range between 21 in 2012, to 69 percent in 2010 .

[Table 2 about here.]

\subsection{Empirical Strategy}

For the 2009 teacher screening test administration, only applicants with scores at or above 60 points were eligible for a public sector teaching position, as determined ex-ante by Ministry of Education officials. Figure 1 shows that the rule generates a highly non-linear relationship between score points and the probability of obtaining a public sector teacher position around the 60-point cutoff, which has been normalized to be zero throughout.

Three aspects of Figure 1 are worth highlighting. First, very few applicants below the test-score obtains public sector teaching positions. This confirms that the cutoff rule was generally binding. Second, there is a dis- 


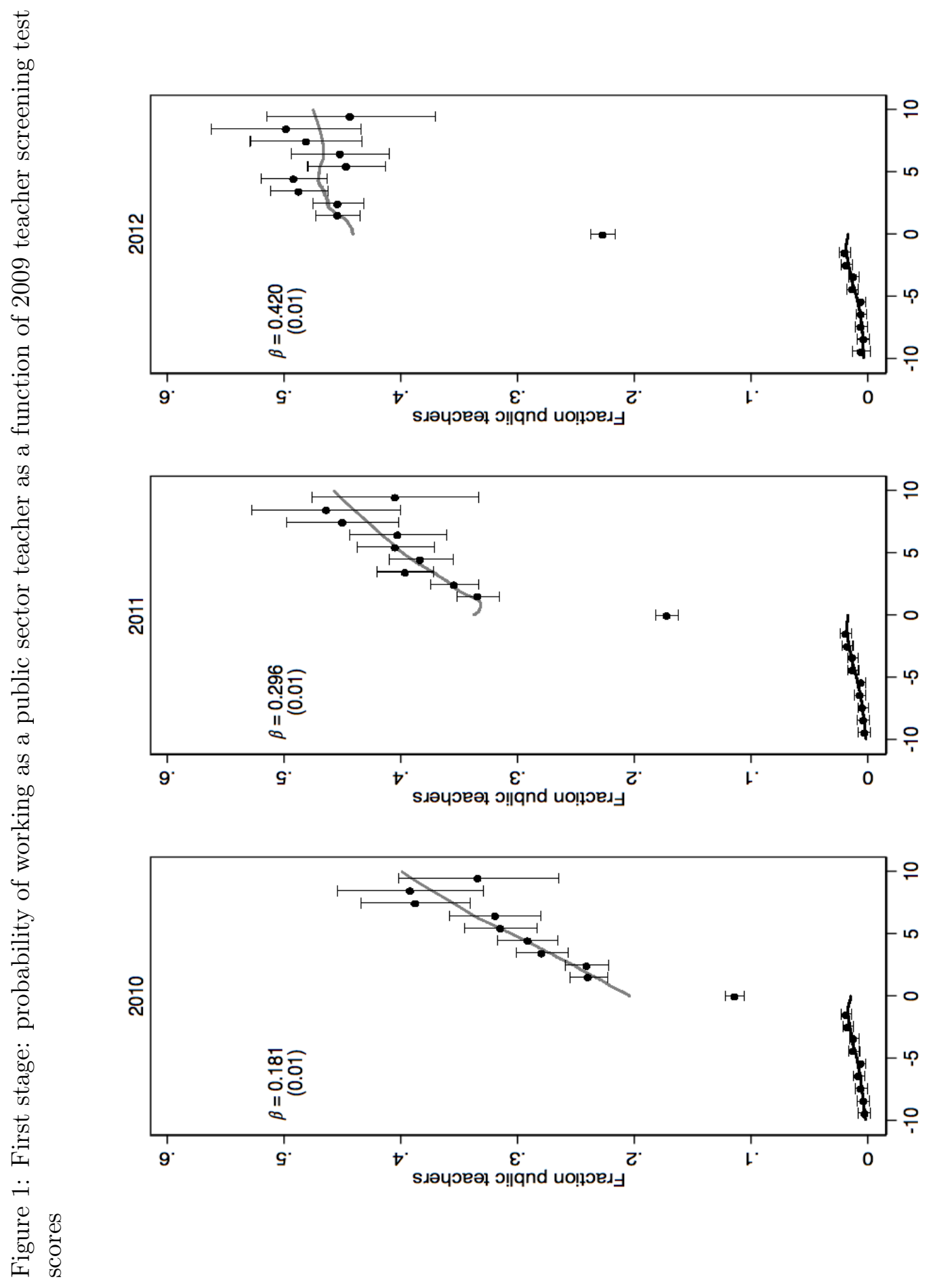

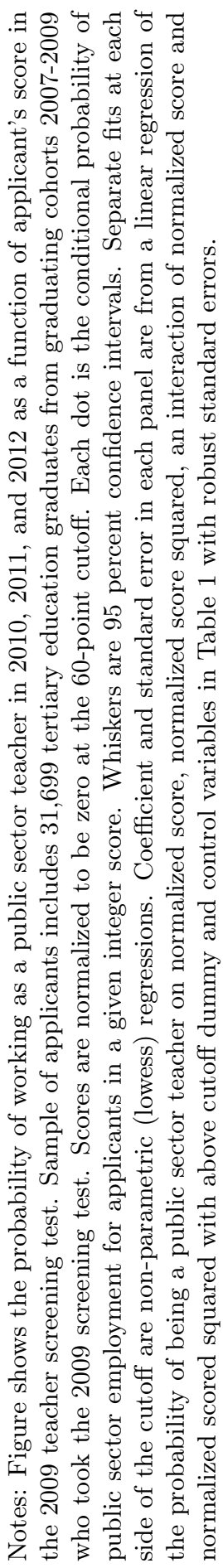


continuity around zero (normalized score) in the probability of obtaining a public sector position. Third, the discontinuity at the cutoff grows in magnitude over time.

The discontinuity grows over time because public sector teaching positions are filled in a descending priority order beginning with the highest scores. Many applicants who meet the admission cutoff do not obtain a public sector position immediately, because in any given year there are more eligible applicants than vacancies. As more vacancies open up over time, these applicants are offered positions. This assignment rule also explains why the slope to the right of zero flattens over time: applicants with lower scores gain access to new vacancies. The first stage ranges from 23 percent in 2010 to close to 50 percent in 2012 .

The reduced-form regression equation we estimate is:

$$
Y_{i}=\alpha_{0}+\alpha_{1} \text { Eligibily }_{i}+F\left(\text { Score }_{i}\right)+X_{i}^{\prime} \delta+\varepsilon_{i}
$$

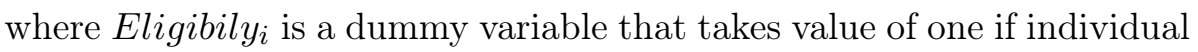
i had a score of 60 or more points in the screening test, Score $_{i}$ represents the score in the screening test normalized to be zero at the 60-point cutoff and $X_{i}$ a vector of covariates that we include in some specifications as a robustness check. We impose $\mathrm{F}($.$) to be a quadratic function of the normalized score.$

As Figure 1 shows, not all individuals with a qualifying score necessarily end up working as public sector teachers. To estimate the effect of obtaining a public sector position on labor market outcomes, we instrument obtaining a position with the Eligibility variable, which as Figure 1 shows, produces 
a very strong first stage. The regression equations that we estimate in this Fuzzy Regression Discontinuity research design are:

First Stage:

$$
P\left(T_{i}\right)=\pi_{0}+\tau_{1} \text { Eligibility }_{i}+F\left(\text { Score }_{i}\right)+X_{i}^{\prime} \delta+\varepsilon_{i}
$$

Second stage:

$$
Y_{i}=\pi_{0}+\tau_{1} P\left(T_{i}\right)+F\left(\text { Score }_{i}\right)+X_{i}^{\prime} \delta+\varepsilon_{i}
$$

Without the vector $\mathrm{X}$ of controls, $\tau_{1}$ is identical to the IV-Wald estimator, equivalent to the ratio of the reduced form in the outcome of interest at the cutoff to the first stage of the probability of obtaining a public sector position at the cutoff.

\section{Validation of the Regression Discontinuity Re- search Design}

The plausibility of the regression discontinuity approach rests on the assumption of continuity of potential outcomes at the eligibility cutoff. We show three pieces of evidence in support for this assumption: the density of screening test scores at the cutoff, covariate continuity at the cutoff and continuity of pre-test labor market outcomes.

The density of scores around the admission cutoff does not evidence any discontinuous jump that would indicate manipulation (Figure 2). Therefore, 
we feel confident that manipulation of applicants' position relative to the cutoff is not a concern in our setting, even despite the possibility of test retake.

Figures 3 and 4 show evidence of covariate continuity around the eligibility cutoff. On Figure 3, we examine the smoothness of gender (female), proportion of graduates from a public university, proportion of graduates that received financial aid, and proportion of graduates that graduate on time. Figure 4 shows graduation year, proportion of graduates from a certified higher education institution and college reputation measured by average college entry test scores of graduates. As these figures show, there is no evidence of discontinuities at the eligibility cutoff in the characteristics of education graduates taking the 2009 teacher-screening test.

The most compelling evidence in support for the validity of the RD design strategy in this settings come from an examination of continuity in pretest labor market outcomes. Figure 5 shows annual earnings, labor supply (payroll days/year), and daily wage in 2008, the year prior to the test administration. Results show continuity of these different labor market outcomes before the teacher test, further substantiating the validity of the regression discontinuity research design.

\section{Results: Public Teacher Applicants at the Mar- gin}

In this section we report regression discontinuity-based results on total annual earnings, labor supply and daily earnings in the first three years after 


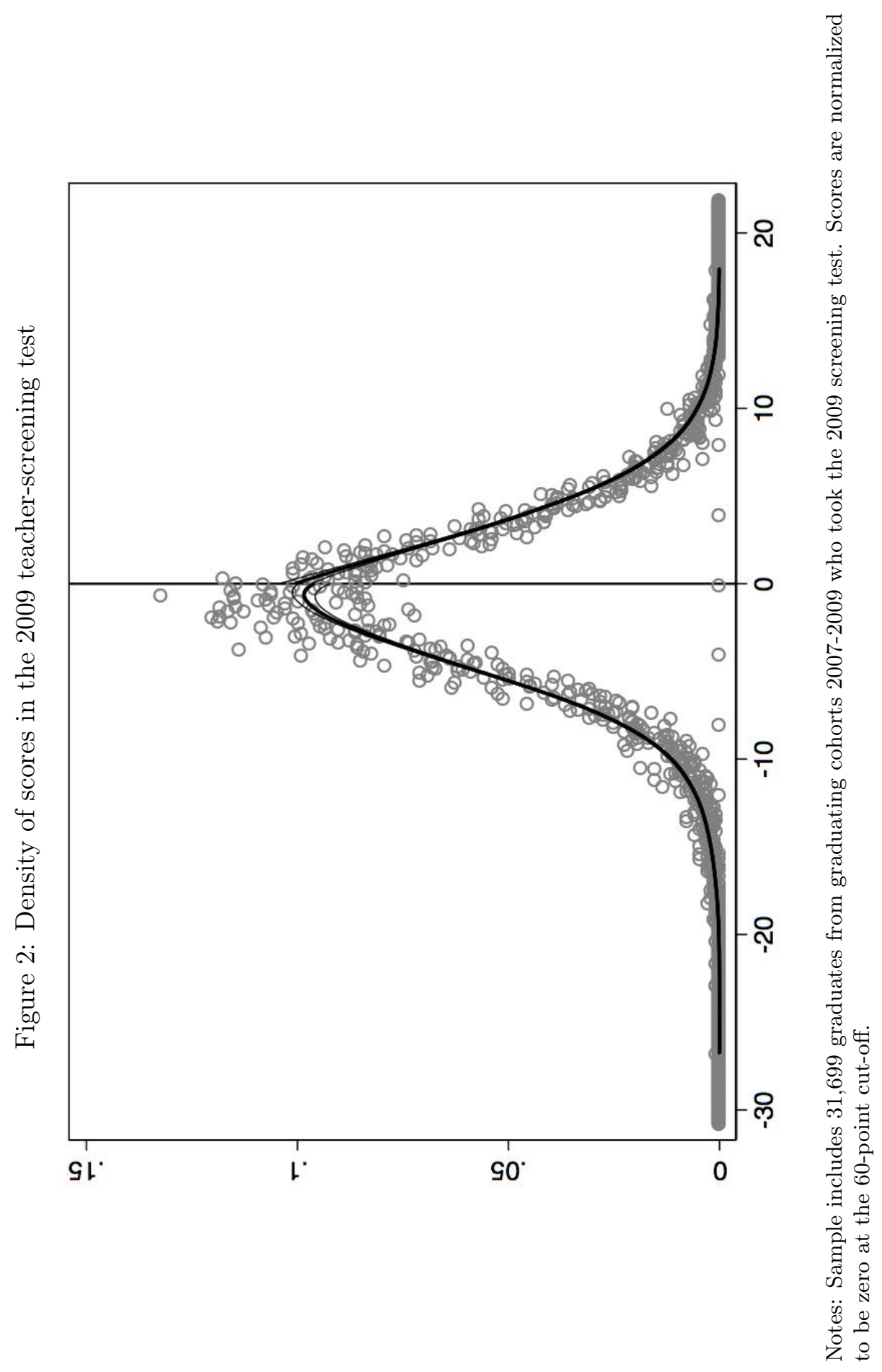



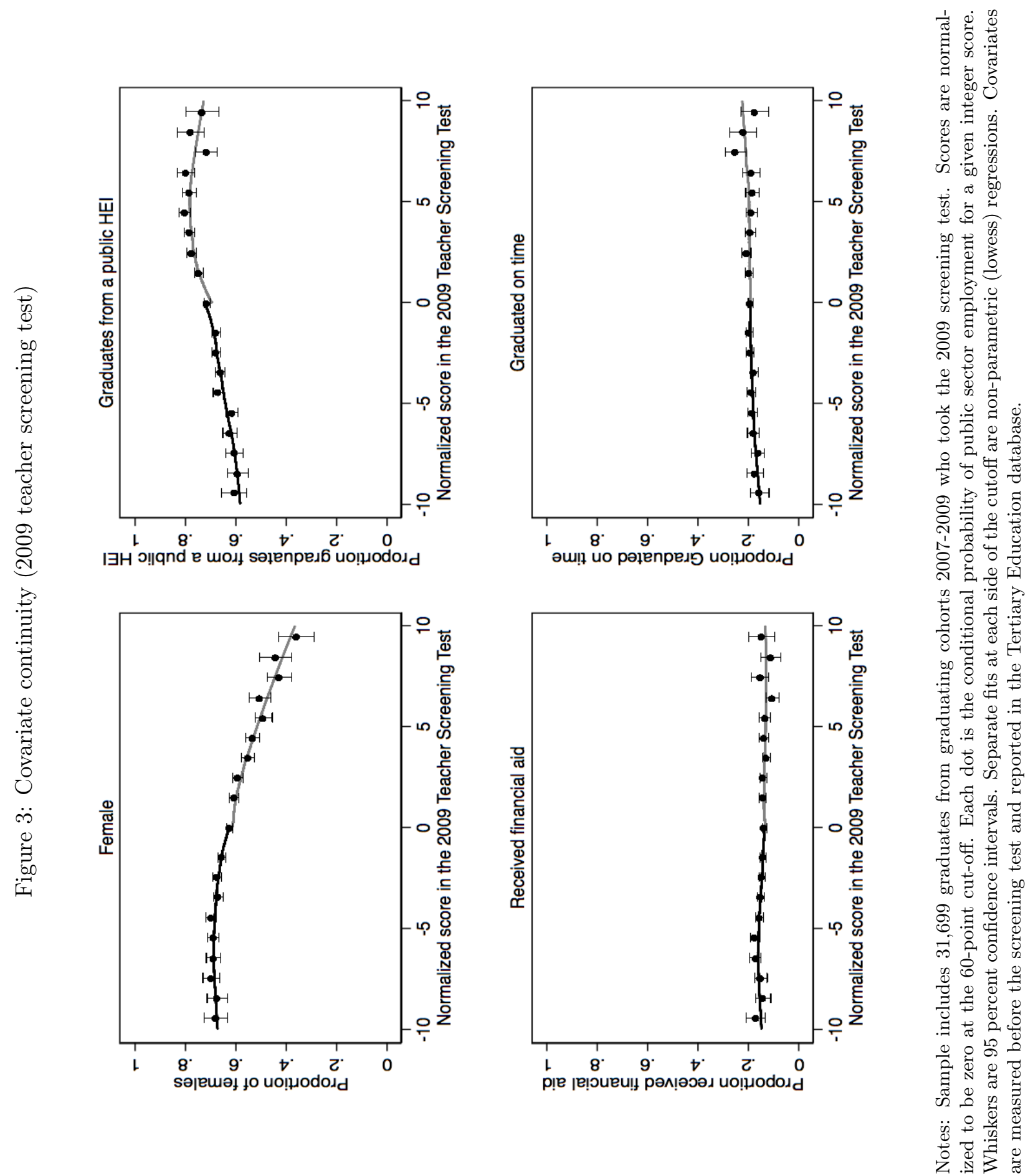

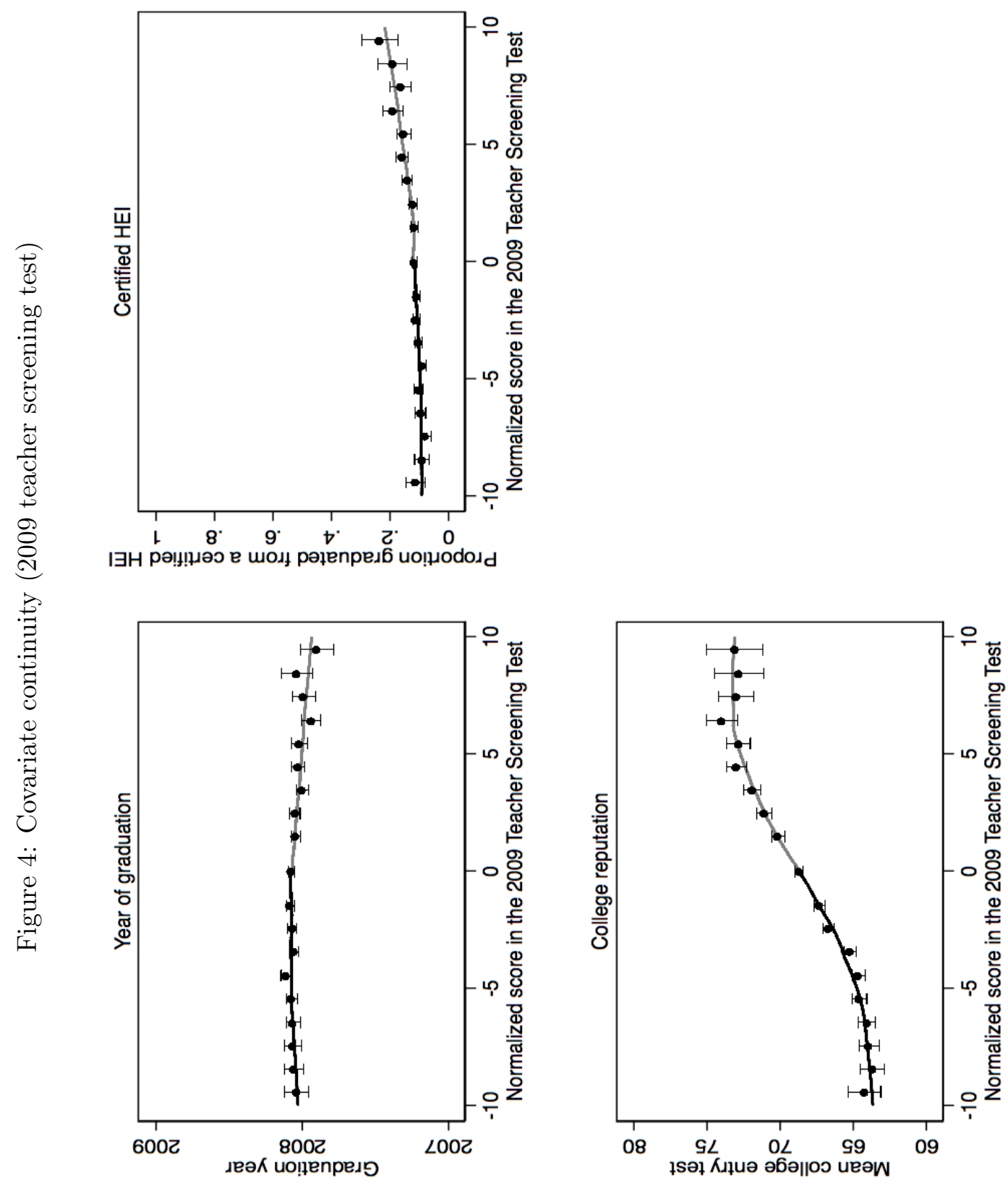

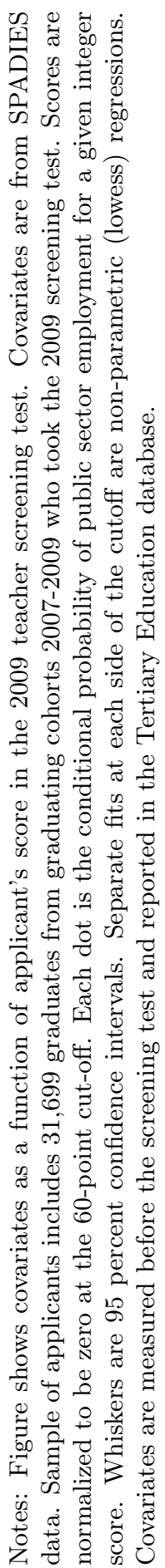




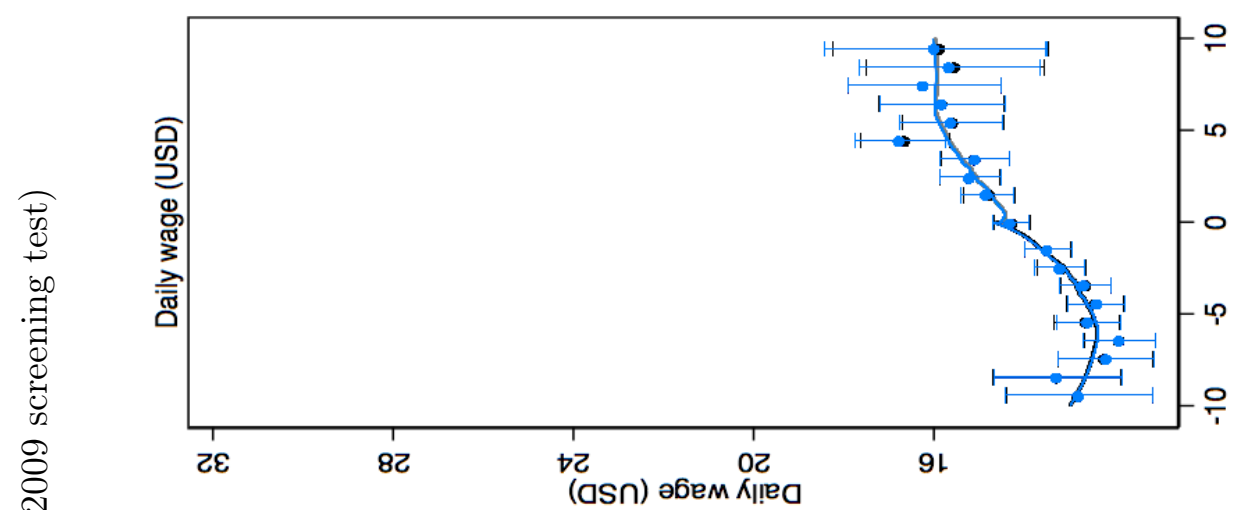

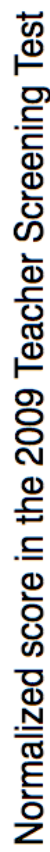

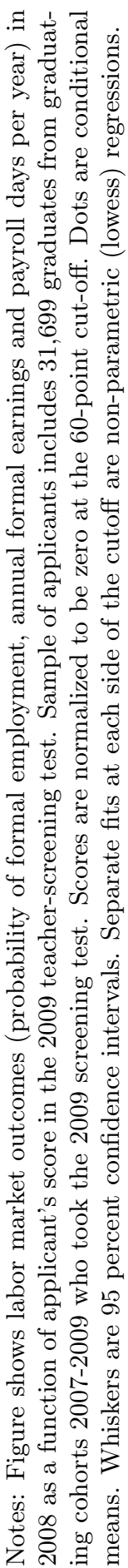


applicants took the 2009 screening test (subsections 5.1, 5.2, and 5.3, respectively) 5 We then present evidence on the distribution of outside occupations (subsection 5.4) and the relevance of the LATE treatment parameter in this context (subsection 5.5). We conclude the section with a theoretical explanation of findings (subsection 5.6).

\subsection{Annual Earnings}

We use two annual earnings measures: annual earnings from the main occupation and total annual earnings (from all occupations). In a given year, annual earnings from the main occupation are annual earnings (including zeros) from the teacher payroll from test-takers who work as teachers; and annual earnings from the occupation with the highest number of payroll days/year for test-takers who do not work as teachers--these earnings would show up in social security records. Total earnings for all occupations are the sum of public teacher payroll earnings and social security earnings, including zeros. Recall that these two data sources measure earnings from mutually exclusive jobs.

Figure 6 shows total annual earnings around the screening test eligibility cutoff. The blue, lighter labels refer to earnings from the main occupation and the black, darker labels refer to earnings from all occupations. Dots are conditional means with corresponding 95 percent confidence intervals. The fit is a non-parametric (lowess) fitted separately to each side of the cutoff. Earnings are an increasing function of scores on the teacher screening test. Analogous fuzzy RD results are shown in Table 3.

\footnotetext{
${ }^{5}$ Monetary figures are in 2013 US dollars throughout.
} 


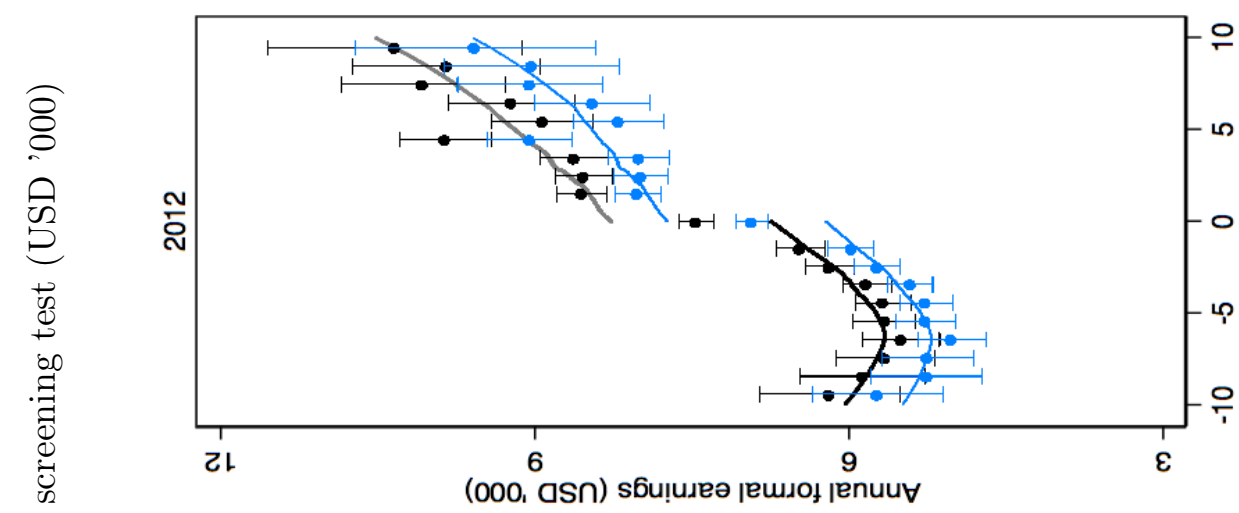

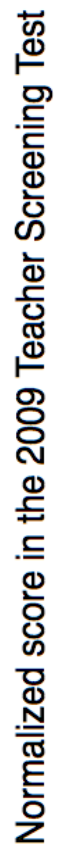

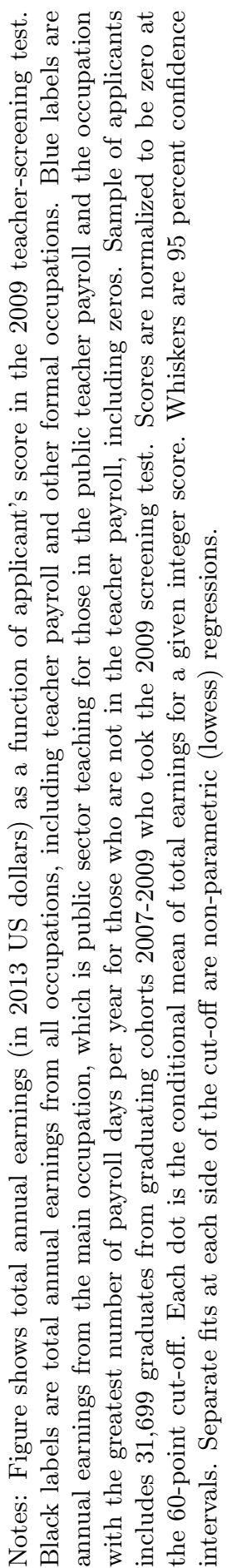


The first result we highlight from Figure 6 is the jump at the cutoff in annual earnings for all test takers. Recall that because in Colombia any college graduate can take the teacher screening exam, the full sample includes education graduates and graduates of other majors. Scaling up these differences at the cutoff by the corresponding probability of being a public sector teacher implies an annual earnings premium of $\$ 2,400$ relative to those below the cutoff in 2010 and $\$ 3,900$ more in 2012 (see Table 3). Relative to the control group mean, test-takers above the cutoff earn 48 percent more in 2010 and 65 percent more in 2012, after three years of potential teacher tenure.

The second key result from Figure 6 is that the annual earnings jump at the cutoff is larger when we look at earnings from all occupations (see darker black line vs. lighter blue line). Adjusting for the probability of becoming a public school teacher, the annual earnings premium in all three years is about 65 percent over control group earnings. This total earnings advantage is initially driven by the outside option or second job. In the first year as public sector teachers, 38 percent of the total annual earnings premium (from all occupations) is the result of earnings from outside jobs. In the second year this decreases to about 10 percent, and by the third year almost the whole premium is driven only by the main teaching job (see Table 3 ).

[Table 3 about here.]

The third key result is shown in Table 3, where the analyses are disaggregated by education and non-education college graduates. Table 3 shows that education and non-education majors have slightly different premia, although 
these differences are not statistically significant (Column 7, Table 3). The impact of being a public sector teacher is positive for education graduates, whose initial premium is 38 percent over the control group and rises to 78 percent after three years. Non-education graduates who become teachers earn 65 percent more than the non-education majors control group in the first year from teaching, and 67 percent by the third year (2012).

The earnings premium from all occupations in the first year for education graduates is 53 percent, and for non-education majors it is 88 percent. By the third year, however, the all-occupations premium is almost equivalent for these two groups at around 62 percent. In other words, after a couple of years as teachers, both education and non-education majors derive little earnings advantage from their second job. Most of their earnings advantage relative to the control group stems from their teaching position.

\subsection{Labor supply}

Labor supply is the number of payroll days per year in formal employment. Labor supply is an increasing function of scores on the teacher screening test (Figure 7). The corresponding regression results are on Table 4. Relative to graduates just below the eligibility cutoff, individuals who are just above the screening test cutoff work more payroll days per year, both in the main occupation (lighter line, blue) and in all occupations combined (darker line, black). The difference at the cutoff is larger when we account for all occupations, suggesting that increased labor supply of marginal test-takers is the result of more workdays per year in the main occupation as well as additional 
work effort in other occupations. ${ }^{6}$

When instrumenting being a public sector teacher with Eligible, we find that in the first year after taking the teacher screening test, public sector teachers work 78.5 additional days the first year in their main occupation over the control group, and 135 days in all occupations over the control group in 2012 (Table 4, Column 2). In the first year after taking the test (2010), additional days in other jobs accounts for 42 percent of the premium from all occupations in the full sample.

[Table 4 about here.]

The number of additional payroll days worked by public sector teachers over the control group decreases over time to 127 days over the control group in 2012 in their main occupation, and 132 for all occupations. After three years of potential teacher tenure almost all of the difference in additional labor supply relative to the control group is coming from the main occupation. The pattern is similar for education and non-education graduates, with the exception of the first year after taking the test. In this initial year, education graduates split their additional labor supply in the first year almost evenly between their main job and other jobs. Non-education graduates exert most of their additional labor supply in their other jobs (presumably, non-teaching jobs).

\footnotetext{
${ }^{6}$ Our data do not have hours worked, only days worked per year in each occupation. We do not know the number of hours worked each day for each individual.
} 


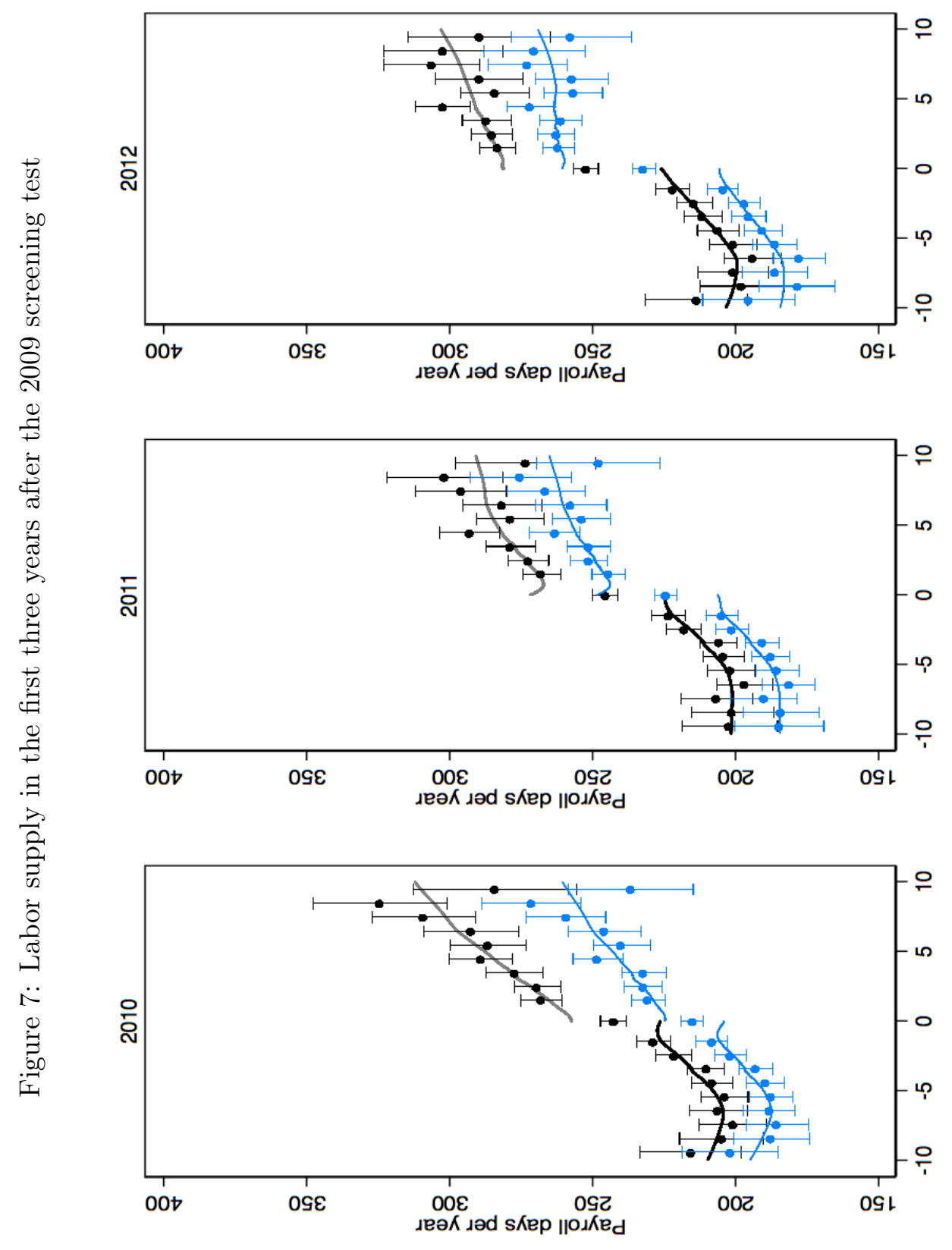

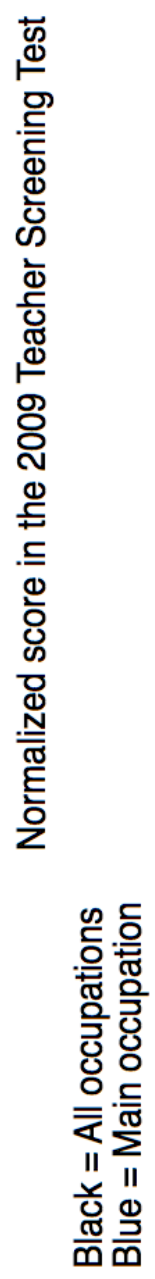

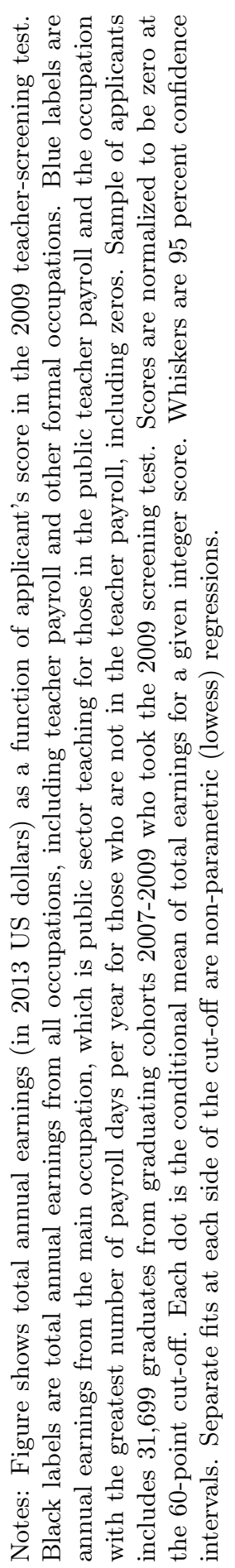




\subsection{Daily Earnings}

Daily earnings per year are total annual earnings divided by total payroll days per year. We compute daily earnings for the main occupation and for all occupations. Just as it was the case with total annual earnings and labor supply, daily earnings are also an increasing function of scores on the teacher screening test (see Figure 8).

Relative to all college graduates that take the teacher screening test and place just below the cutoff, those about the cutoff have greater daily earnings in the main occupation (blue), as evidenced by the discontinuous jump at the cutoff (see Figure 8).

When we instrument being a public sector teacher with Eligible, we find that in the first year after taking the test, public-school-teachers earn a daily earnings premium of $\$ 1.8$ per day in their main occupation (teaching). This daily premium is not statistically significant (see Table 5, Column 2). The daily earnings in the main occupation increases with potential experience to $\$ 6.1$ per day in 2011 , and $\$ 7.0$ per day in 2012 . Results are similar - even though point estimates are slightly smaller-when we estimate the daily earnings premium from all occupations (Table 5, Column 2, bottom panel).

There are small differences in the daily earnings premium for education and non-education majors, although these differences are not statistically

significant (Table 5, Column 7). In addition, several estimates of the daily earnings premium are not statistically significant for non-education graduates (Table 5, Column 6).

[Table 5 about here.] 


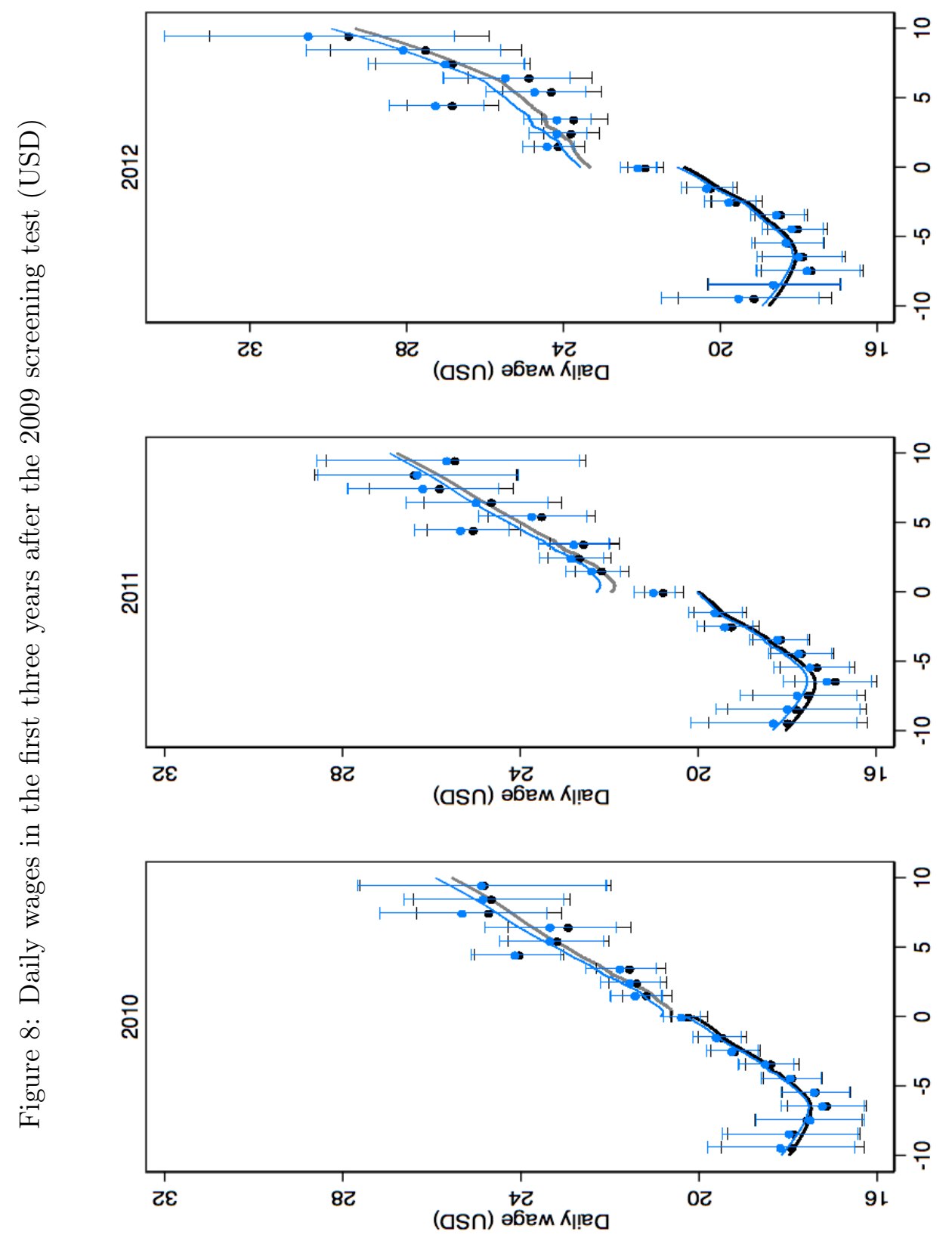

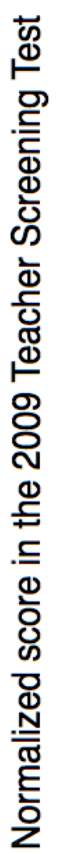

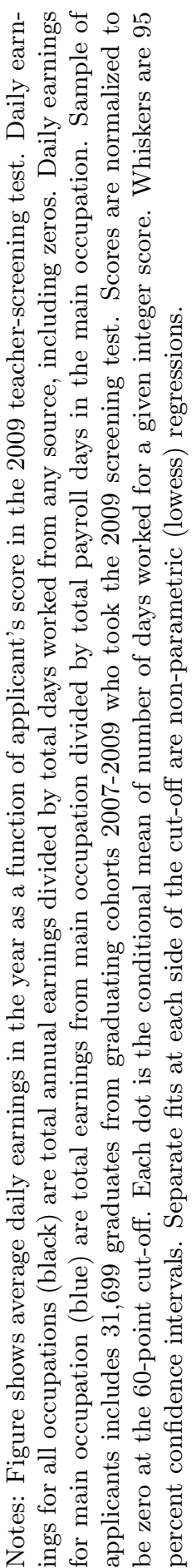


The daily earnings results suggest that the total annual earnings premium for public sector teachers in the main occupation (teaching) is - at the margin - a combination of a labor supply and a wage effect. The daily earnings premium from all occupations for public sector teachers at the margin is, however, mainly a labor supply effect.

\subsection{Outside Occupations}

The social security database contains 4-digit ISIC occupation codes. 7 These codes are available for 2008, 2010, 2012, and 2013. In these years, however, there are changes to the ISIC revision (Rev 3 or Rev 4) codes reported in the data. For education-related occupations, the codes are mostly consistent across revisions, but not entirely ${ }^{8}$ Due to this inconsistency, we code occupations as being education related in two ways. First, we only code as education-related occupations for which the occupation classification is unambiguously related to education in both revisions. This method captures the majority of education related occupations. This first approach provides a lower bound estimate of the probability of working in a private, education-

\footnotetext{
${ }^{7}$ ISIC stands for International Standard Industrial Classification of All Economic.

${ }^{8}$ Education codes in CIIU Rev. 3 are numbers: 8011 (preschool), 8012 (primary), 8021 (middle school), 8022 (high school), 8030 (higher education) and 8090 (other types of education). Of this only 8030 is used in Rev. 4 for a different activity (detectives and private investigators). Education codes in CIIU Rev. 4 are 8511 (early childhood), 8512 (preschool), 8513 (primary), 8521 (middle school), 8522 (academic high school), 8523 (technical high school and job training), 8530 (institutions that combine different levels of education), 8541 to 8544 (technical and professional), 8551 to 8553,8559 (other types of education), 8560 (other activities related to education). Among these three codes are used in CIIU Rev. 4 for different activities: 8511 (health services institutions), 8512 (medical practice activities), 8513 (dentistry activities). When assuming that all codes that refer to education in Rev. 3 or 4 correctly identify a worker of the education sector we will assume that codes 8030, 8511, 8512 and 8513 effectively identify workers from the education sector. In the second case we will assume that these four codes identify workers in other sectors.
} 
related job 9

The second approach assumes that occupations in codes that in one revision are education-related and in the other revision are not, are all educationrelated. This approach produces an upper bound of the proportion of workers in education related occupations. The bounds are quite tight. In Figure 9 we show outside occupation distributions based on the lower bound codification.

The occupational distributions for test screening test takers below the cutoff and for those above the cutoff who do not work as public sector teachers are similar, in 2010 (one year after the test, Figure 9). As can be seen in Figure 9, about 8 and 5 percent, respectively, of test takers below the cutoff or above the cutoff but not working as a public sector teacher work in an education related occupation outside of their main job. The two important occupational categories in terms of holding a second job after the test application for these two groups of applicants are real estate, business, and finance, and other services. Among public sector teachers, only about 3 percent work in a formal education related outside occupation 10 The majority of public sector teachers with a second occupation work in real estate, business, and finance, and other services 11

To the extent that the skills required in those outside occupations differ from those skills mostly needed and honed through teaching, it seems plausible that there may be little skill complementarity between public sector teaching and outside jobs. There is however, a scheduling complementarity

\footnotetext{
${ }^{9}$ Recall that the social security database does not cover public sector teaching.

${ }^{10}$ This excludes private student tutoring when this activity takes place under an informal contract between teachers and parents.

${ }^{11}$ Results are similar for 2012 and shown in the Appendix.
} 


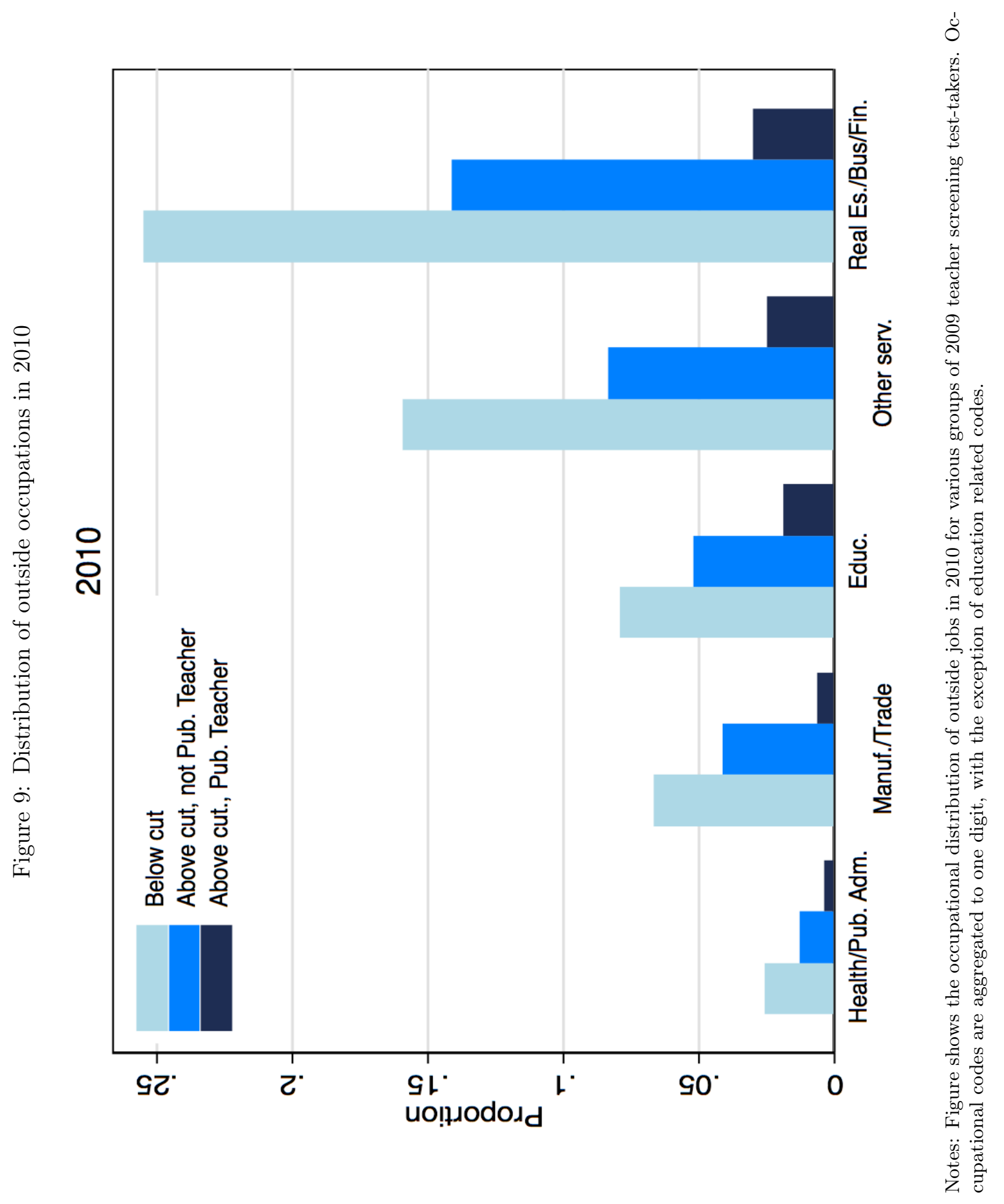


in public sector teaching. Schools in Colombia, as in much of the developing world, operate in two-shifts: a morning and an afternoon shift.

Each shift is about 4 hours long, and constitutes a half-day school day relative to the length of the school day in the United States. These double shifts facilitate lumpy time allocations of public school teachers to outside occupations.

\subsection{LATE and the Distribution of Earnings for All College Graduates}

Most of the discussion about raising the quality of public sector teachers centers on how to attract top college graduates into the teaching profession (e.g. Garcia et al 2014; Bruns and Luque 2014). It could be argued that the earnings premia and labor supply effects documented in this paper are only local to the teacher screening test cutoff, in other words, for the potentially least desirable eligible candidate. Two pieces of evidence suggest that - at least in the Colombian context - this LATE causal parameter is relevant for the larger population of teacher candidates. First, it is worth considering that over one third of public sector teachers in Colombia are not college graduates. Thus, even the most marginal eligible applicant on the teacher test will have a college degree, something which has been found to predict higher student test scores in developing countries, particularly in secondary schools and in rural areas (Glewwe et al., 2011; Santibañez, 2006).

Second, even compared to college graduates from all majors, those at the cutoff do not look disproportionally negatively selected in the overall earnings distribution (Figure 10). Two years after the screening test, for 

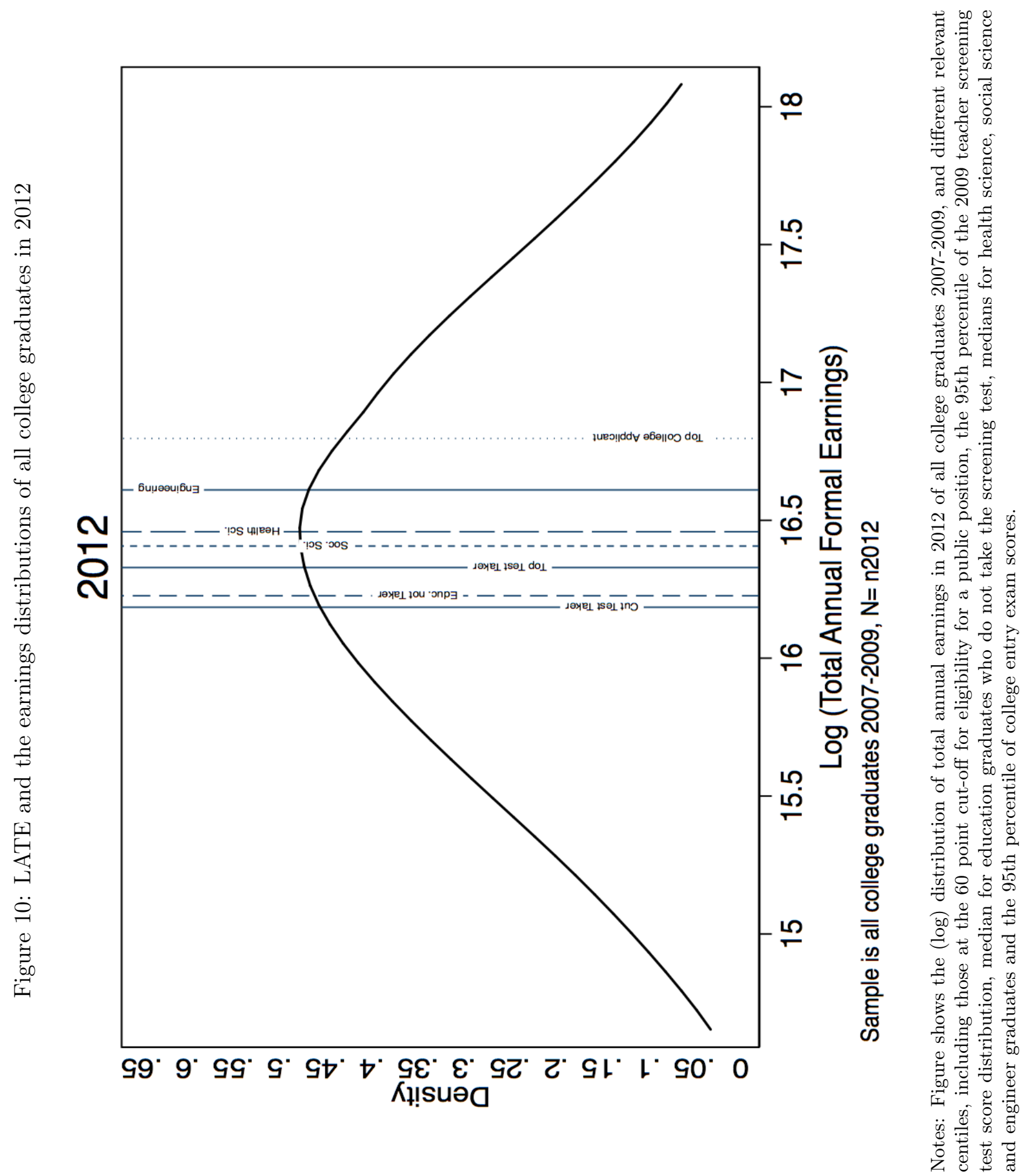
example, education college graduates who take the teacher screening test and score at the eligibility cutoff rank at about the 45th percentile in the earnings distribution of all graduates. Education college graduates who score at the 95th percentile in the screening test ("top test taker") have annual earnings above those at the cutoff in 2012. Median graduates from health sciences, social sciences, engineering, those education graduates who do not take the screening test, as well as the top college applicant are well above the cut test taker. In sum, these figures suggest that, even though public teaching in Colombia is not attracting the top college graduates, education graduates who score at the margin of the screening cut off earn near the middle of the earnings distributions for all college graduates.

\subsection{Theoretical Explanation of Findings}

Our analyses thus far suggest that public sector teachers earn a significant labor market earnings premium over applicants at the margin who did not obtain a public teaching position. Initially, a significant portion of this premium is the result of additional labor supplied in an outside job, many of which are non-teaching jobs. Teachers who have more outside options (i.e. graduates from non-education majors) tend to hold these outside jobs in higher proportion than teachers from education majors.

Conceptually, we can explain these findings in a simple labor supply and demand model in which there are two types of jobs that differ along three dimensions. In the teaching job, workers have stability but face restrictions on the number of hours worked and have a pay schedule that is determined by a central planner with no regional variation. In the non-teaching job, there is 
no stability but workers can work as many hours as they wish to and workers are paid marginal product of labor, determined by local market clearing conditions. Workers differ in their intrinsic motivation to hold an additional job, which may stem from differences in reservation wages (e.g. Shishko and Rostker, 1976) or tastes (e.g. Conway and Kimmel, 1998; Dickey, Watson and Zangelidis, 2011). The existence of local labor markets and moving costs create regional variation in the equilibrium wage gap between teaching and non-teaching jobs (e.g. rural vs. urban). Differences in reservation wages (e.g. education graduates vs. graduates from other majors) or tastes help explain why within regions we see some public teachers holding outside jobs and others not.

\section{Earnings Premium for Infra-marginal High-Scoring Applicants}

Most of the discussion about teacher pay concerns ways to attract top talent into the teaching profession. One potential shortcoming of our RD framework is that we identify impacts that are local to the teacher screening test cutoff. Even though prospective novice teachers who take the screening test have earnings that are typical of all college graduates nationwide (Figure 10), it is unclear whether we can extrapolate labor market premia for novice public teachers at the margin to inframarginal top teachers.

In this section, we apply the methods of Angrist and Rokannen (2015) to estimate labor market premia for inframarginal teachers. The approach exploits our availability of a large set of baseline predictors other than the 
teacher screening test score running variable. Identification away from the cutoff requires an additional conditional independence assumption (CIA), namely, that the teacher screening test score is ignorable conditional on these additional predictors. Regressions of outcomes on the screening test score and the additional predictors on either side of the cutoff provide a simple test for the CIA. Table 6 shows results of these conditional independence tests.

[Table 6 about here.]

As the top panel of Table 6 shows, conditioning on the test score effectively eliminates the relationship between the running variable and potential labor market earnings, from the main and all occupations. The coefficients are small in magnitude and statistically insignificant. Panel B of Table 6 shows that, among eligible applicants (i.e. those above the scoring threshold), conditioning also eliminates the relationship between the running variable and the probability of being a public sector teacher for 2011 and 2012, that is two and three years after taking the teacher screening test.

We use the conditional independence results from Table 6 to estimate labor market premia for inframarginal public sector teachers who obtained a high score in the screening test. We use a propensity score stratification approach based on a propensity score (logit) model that includes as predictors all variables in the conditional independence test regression models (see notes to Table 6 for details).

The distributions of estimated propensity scores for eligible and ineligible public teacher applicants exhibit substantial overlap across the entire 
support (Figure 11). This guarantees that we can construct valid earnings counterfactuals for eligible applicants over the entire support of the predicted probability of being an eligible public sector teacher.

We estimate and interpret the causal impacts on earnings of being a public sector teachers in an instrumental variable framework, similar to the one employed earlier in the paper. In particular, the first stage is a linear regression of the probability of being a public sector teacher as a function of being eligible, controlling for propensity score strata fixed effects (10 strata, 9 fixed effects plus an omitted category). In the second stage we regress labor market earnings on the predicted probability of being a public sector teacher, also controlling for propensity score strata fixed effects.

Table 7 shows results of this instrumental variables estimation approach. For comparison, columns (1), (3) and (5) of Table 7 reproduce local effects on earnings on earnings of being a public sector teacher in the first three years after the screening test. These estimates correspond to estimates we presented earlier in Table 3. Columns (2), (4) and (6) show impacts on earnings for inframarginal public sector teachers based on the CIA instrumental variables approach. In both the main occupation and for all occupations, labor market premia for inframarginal public sector teachers are statistically significant and larger than the premia for marginal applicants at the cutoff. When looking at all occupations, teachers away from the cutoff earn 5.04 more in thousands of 2013 US\$, than teachers in the control group in 2010. Teachers at the cutoff earn 3.80 more than those in the control group. The difference this initial year after taking the test is 1.24 , or about 32 percent more for teachers away from the cutoff, than teachers at the cutoff. This 


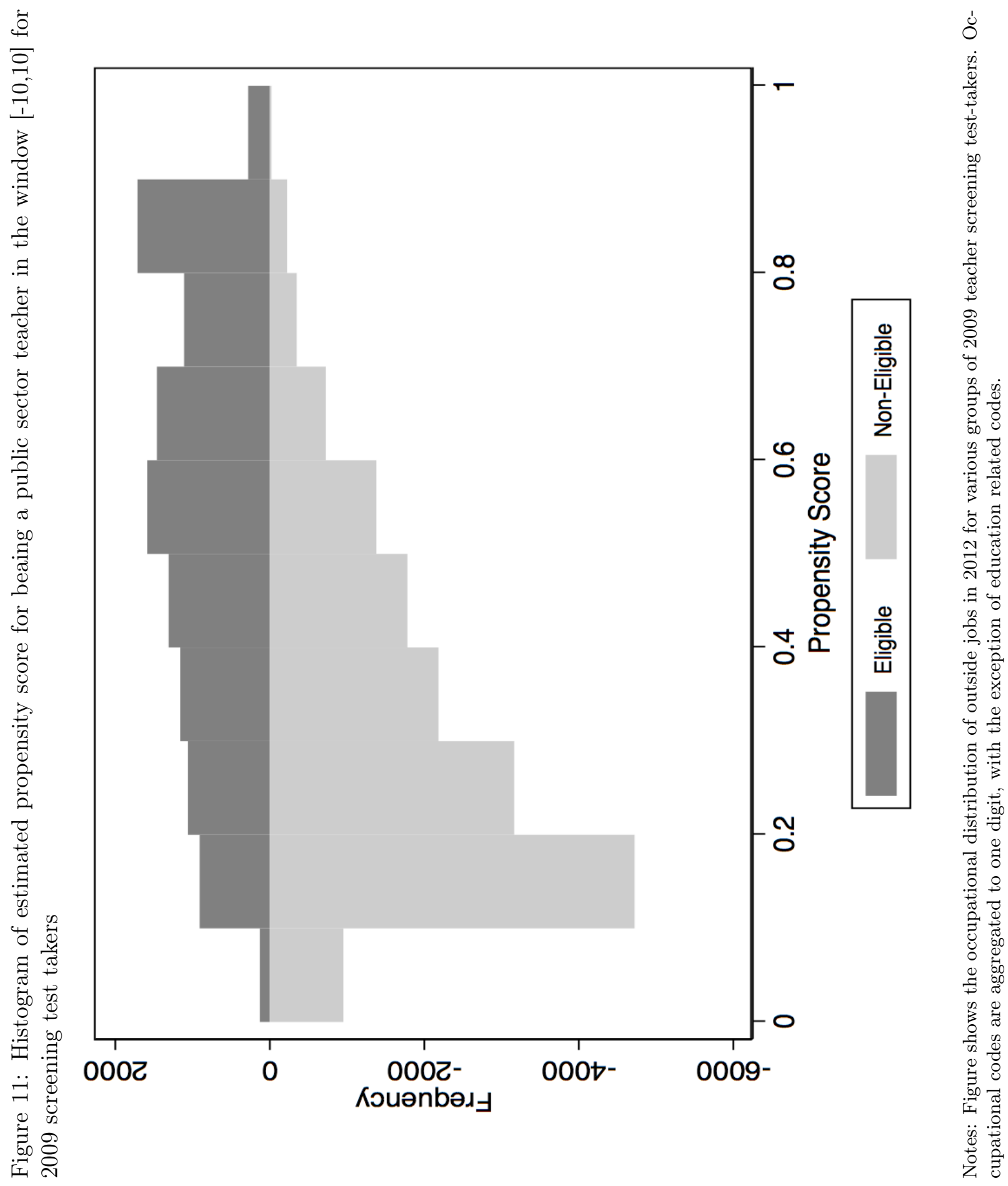


difference decreases to 5 percent in the third year.

[Table 7 about here.]

These results suggest that-relative to their labor market outside options - being a public sector teacher in Colombia is as attractive, if not more, for inframarginal high-scoring applicants as it is for applicants who obtain marginal scores on the teacher screening test. On the whole, results suggest that, at least in the Colombian context, rather than a penalty, novice public sector teachers across all ability levels earn a substantial labor market premium early in their careers.

\section{Conclusions}

In an effort to improve teaching screening, in 2002 Colombia underwent a major education reform changing the way teachers were selected for public school teaching positions. The central piece of the reform was a national, centralized teacher-screening exam. At the heart of these policy efforts is a determination to make the teaching profession more attractive to highly qualified and motivated individuals.

We take advantage of the fact that the screening exam creates exogenous variation on the probability of obtaining a permanent public sector teaching position to examine earnings and labor supply differentials or those graduates that work as public sector teachers against those that work in alternative occupations. In addition, we use a unique dataset that merges four administrative national data sources to observe teacher candidates' labor market outcomes in their teaching job as well as other occupations. 
Applicants who marginally pass the teacher screening test have earnings during the first three years of tenure that substantially greater than earnings of applicants below the test passing cutoff. Part of the initial year earnings premium stems from the fact that a significant portion of public sector teachers hold a second non-teaching job in the formal sector. For less that one-third of teachers this outside job is education-related. By the third year of teaching, the earnings advantage coming from the second job wanes, and almost the entirety of the premium is driven only by the main (teaching) occupation. There are slight differences in the point estimates of these premia for education and non-education majors, although none reach statistical significance at conventional levels.

Relative to applicants below the cutoff, public teachers work harder, both in their teaching job as well as in their second job, as measured by payroll days/year in the first three years of potential teacher tenure.

The total annual earnings premium in the main occupation in the first three years of potential tenure for public sector teachers in the main occupation is - at the margin - a combination of a labor supply and a wage effect. The total earnings premium from all occupations for public sector teachers at the margin is, however, a labor supply effect.

Estimates of the earnings premium for high-scoring infra-marginal applicants suggest that being a public sector teacher in Colombia is as attractive, if not more, for inframarginal high-scoring applicants as it is for applicants who obtain marginal scores on the teacher screening test. On the whole, our evidence suggests that, at least in the Colombian context, rather than a penalty, novice public sector teachers across all ability levels earn a sub- 
stantial labor market premium early in their careers. Our results, therefore, may call into question initiatives that seek to increase teacher compensation under the presumption that novice public teachers are underpaid relative to similarly qualified professionals in other occupations. 


\section{References}

Angrist, Joshua D. and Jonathan Guryan, "Does teacher testing raise teacher quality? Evidence from state certification requirements," Economics of Education Review, 2008, 27 (5), 483-503.

_ and Miikka Rokkanen, "Wanna Get Away? Regression Discontinuity Estimation of Exam School Effects Away From the Cutoff," Journal of the American Statistical Association, 2015, 110 (512), 1331-1344.

Auguste, Byron, Paul Kihn, and Matt Miller, "Closing the talent gap: Attracting and retaining top-third graduates to careers in teaching," 2010, p. $46 \mathrm{p}$.

Bau, Natalie and Jishnu Das, "The Misallocation of Pay and Productivity in the Public Sector: Evidence from the Labor Market for Teachers," World Bank Policy Research Working Paper, 2017, (8050).

Britton, Jack and Carol Propper, "Teacher pay and school productivity: Exploiting wage regulation," Journal of Public Economics, 2016, 133, 7589.

Bruns, Barbara and Javier Luque, Great Teachers: How to Raise Student Learning in Latin America and the Caribbean, Washington: Ther World Bank Group, 2015.

Clotfelter, Charles T., Helen F. Ladd, and Jacob L. Vigdor, "Teacher Credentials and Student Achievement in High School: A Cross-Subject 
Analysis with Student Fixed Effects," Journal of Human Resources, 2010, $45(3), 655-681$.

Dal Bo, Ernesto, Frederico Finan, and Martin Rossi, "Strengthening State Capabilities : The Role Of Financial Incentives In The Call To Public Service," Quarterly Journal of Economics, 2013, pp. 1169-1218.

de Ree, Joppe, Karthik Muralidharan, Menno Pradhan, and Halsey Rogers, "Double for Nothing? Experimental Evidence on the Impact of an Unconditional Teacher Salary Increase on Student Performance in Indonesia," NBER Working Paper Series, 2015, p. 66.

Estrada, Ricardo, "Rules Rather Than Discretion: Yeacher Hiring and Rent," 2013, pp. 1-30.

Garcia, Sandra, Dario Maldonado, Guillermo E Perry, Catherine Rodriguez, and Juan Saavedra, Tras la excelencia docente, Fundación Compartir, 2014.

Glewwe, Paul W., Eric A Hanushek, Sarah D Humpage, and Renato Ravina, "School resources and educational outcomes in developing countries: A review of the literature from 1990 to 2010," 2011.

Holmstrom, B., "Managerial Incentive Problems: A Dynamic Perspective," The Review of Economic Studies, 1999, 66 (1), 169-182.

_ and P. Milgrom, "Multitask Principal-Agent Analyses: Incentive Contracts, Asset Ownership, and Job Design," Journal of Law, Economics, and Organization, 1991, 7 (special), 24-52. 
Kane, Thomas J and Douglas O Staiger, "Estimating Teacher Impacts on Student Achievement: An Experimental Evaluation," National Bureau of Economic Research, 2008, (14607), 51.

Liang, Xiaoyan, "Teacher Pay in 12 Latin American Countries: How Does Teacher Pay Compare to Other Professions, What Determines Teacher Pay, and Who Are the Teachers?," LCSHD Paper Series, 2000, 49 (21493), $59-64$.

Mizala, Alejandra and Hugo Ñopo, "Measuring the relative pay of school teachers in Latin America 1997-2007," International Journal of Educational Development, 2016, 47, 20-32.

Rockoff, Jonah E., "The impact of individual teachers on student achievement: Evidence from panel data," American Economic Review, 2004, 94 (2), 247-252.

Santibañez, Lucrecia, "Why we should care if teachers get A's: Teacher test scores and student achievement in Mexico," Economics of Education Review, 2006, 25 (5), 510-520.

Wang, Aubrey, Ashaki Coleman, Richard Coley, and Richard Phelps, "Preparing Teachers Around the World," Educational Testing Service, 2003, pp. 1-50. 


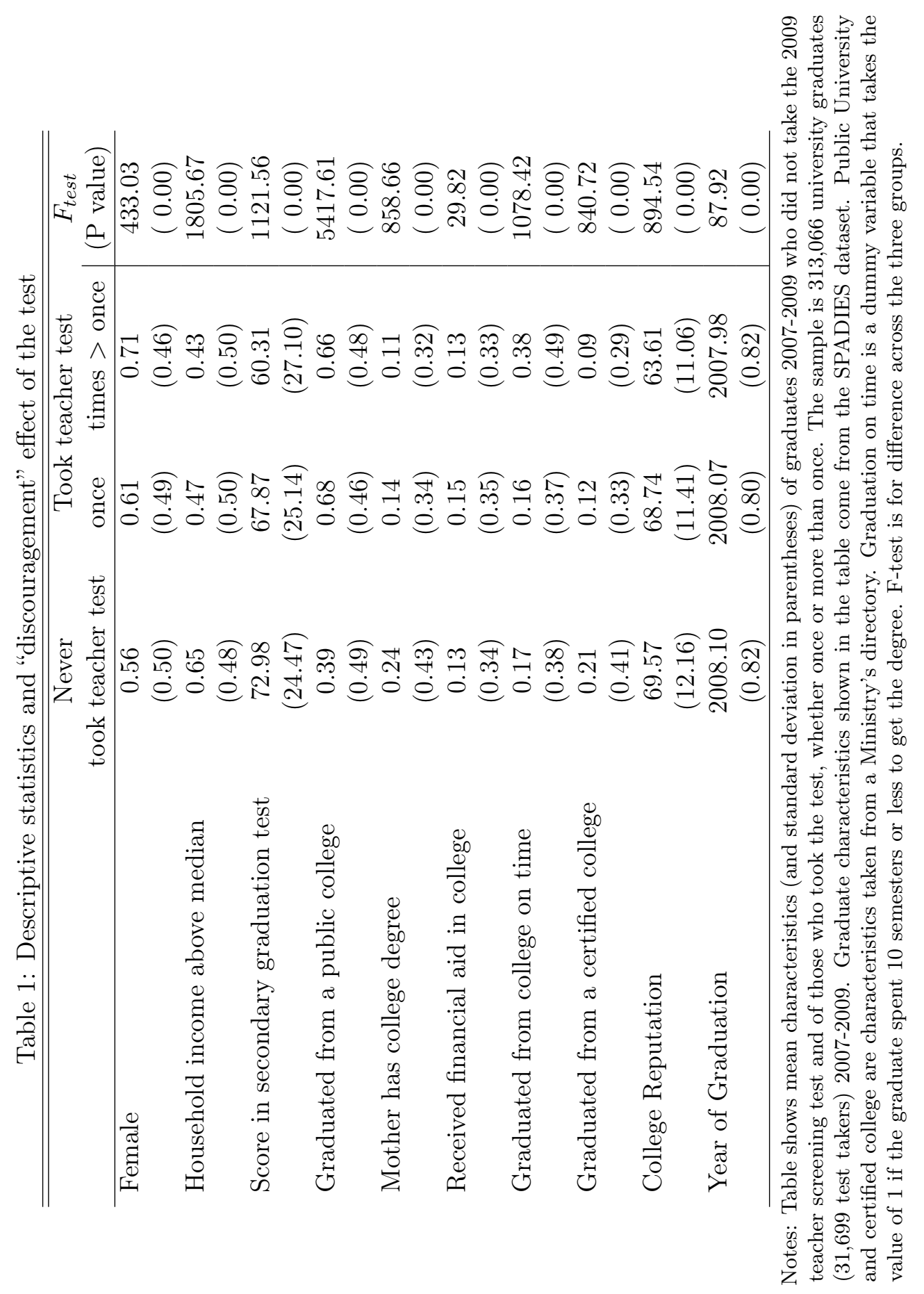




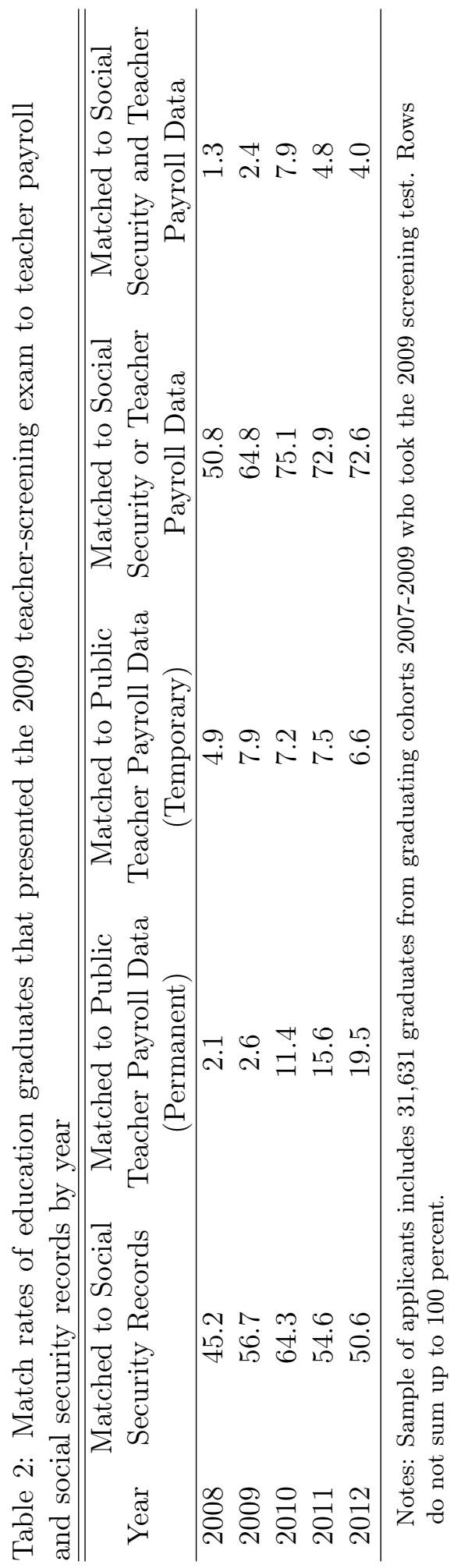




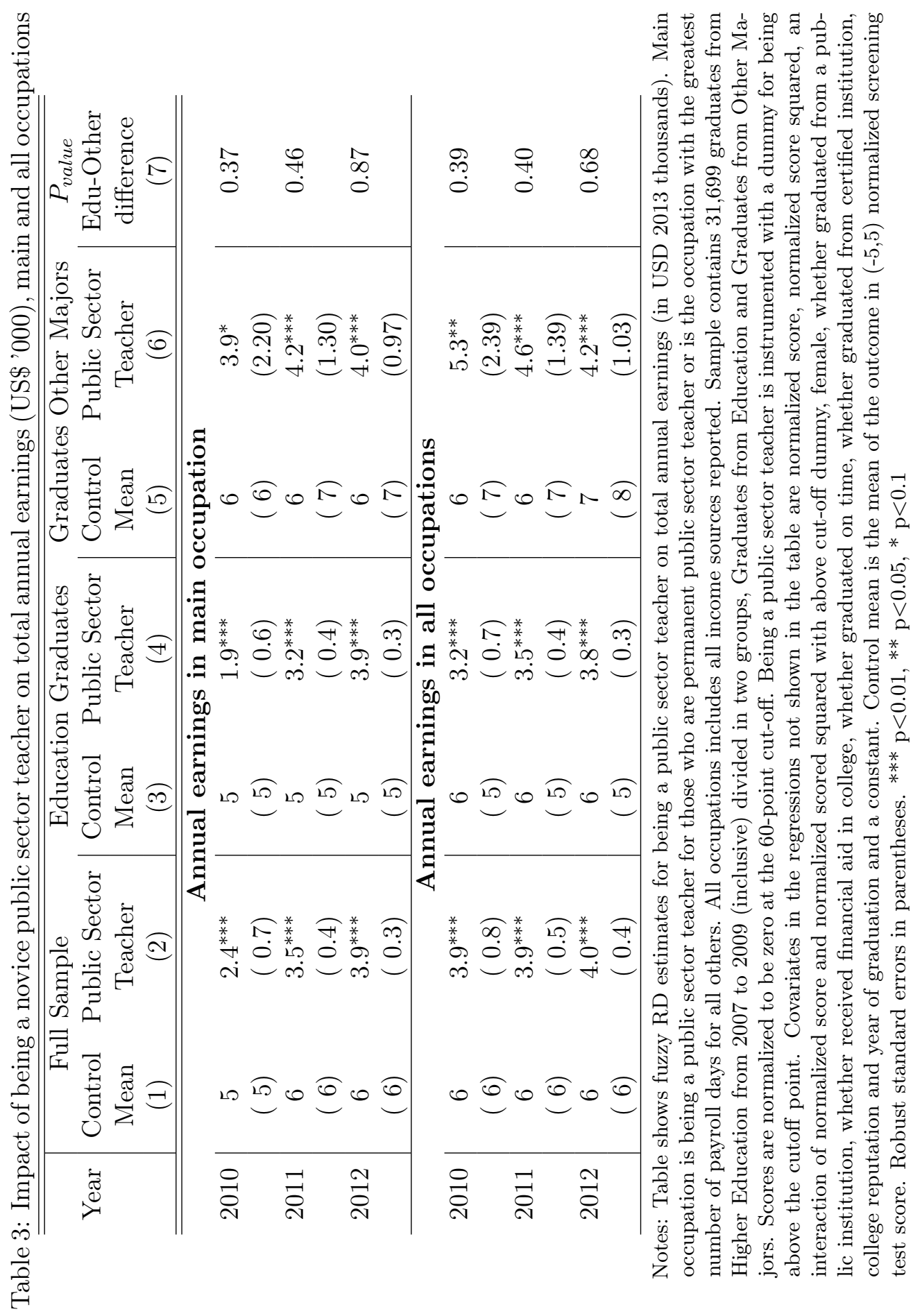




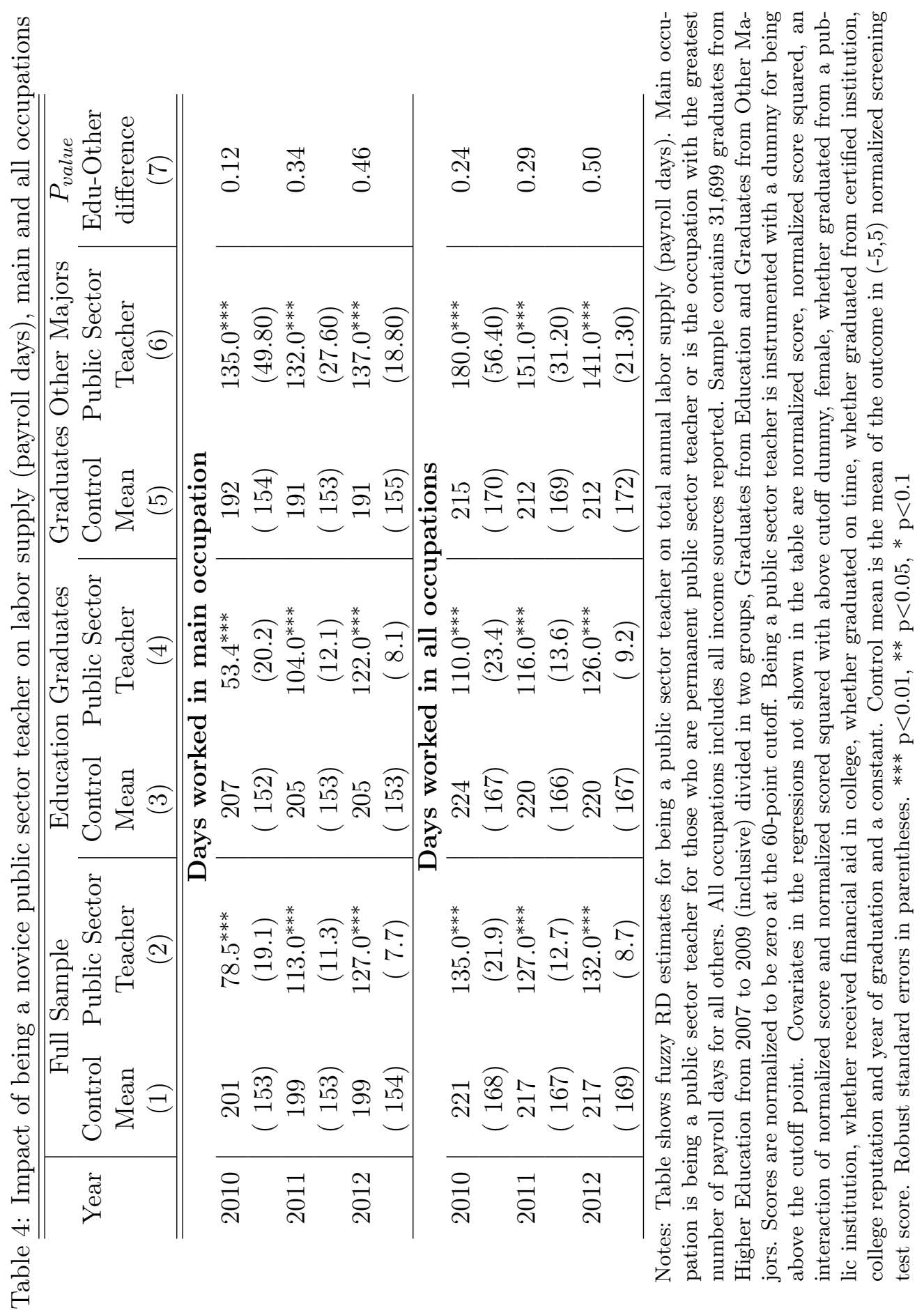




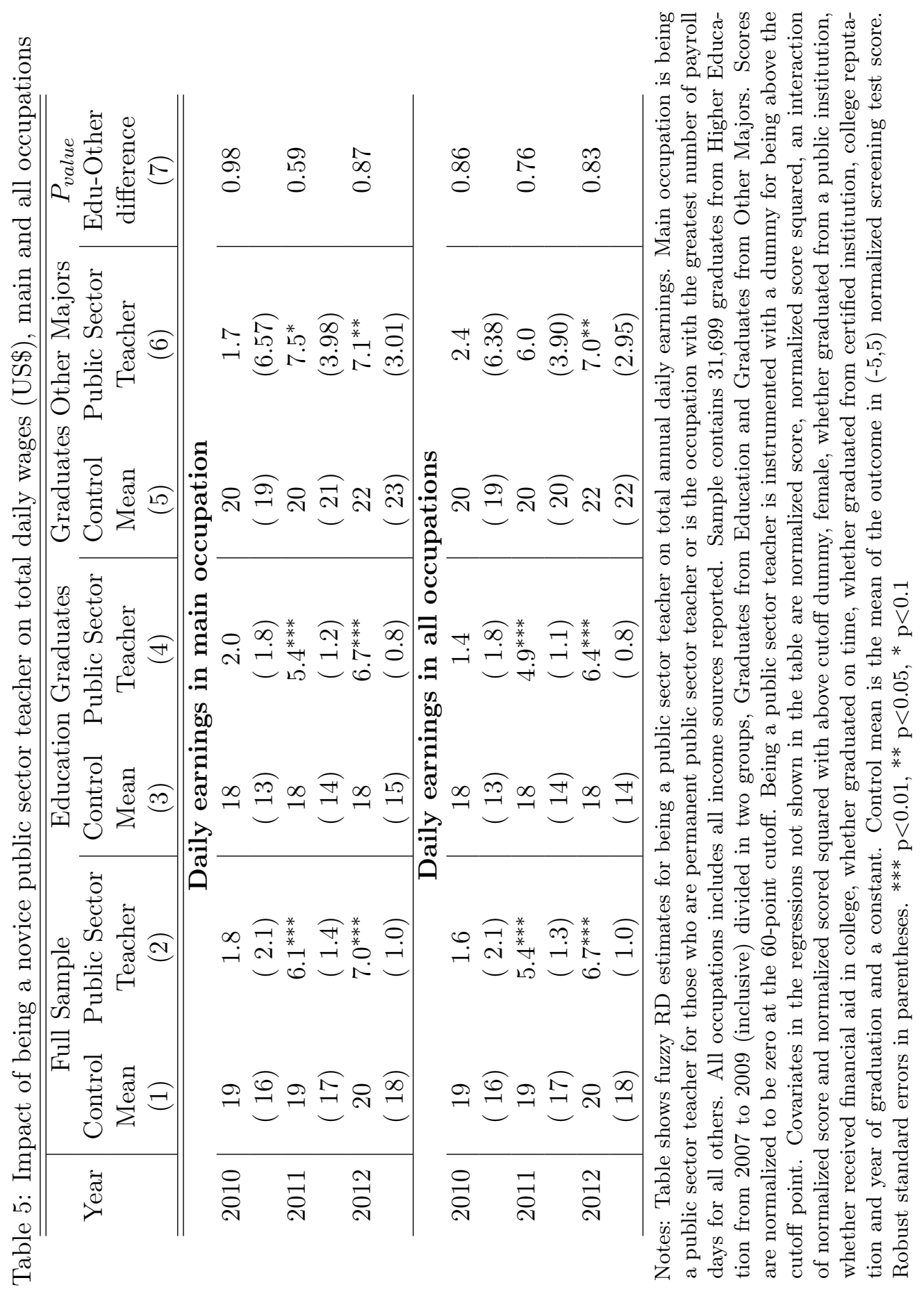




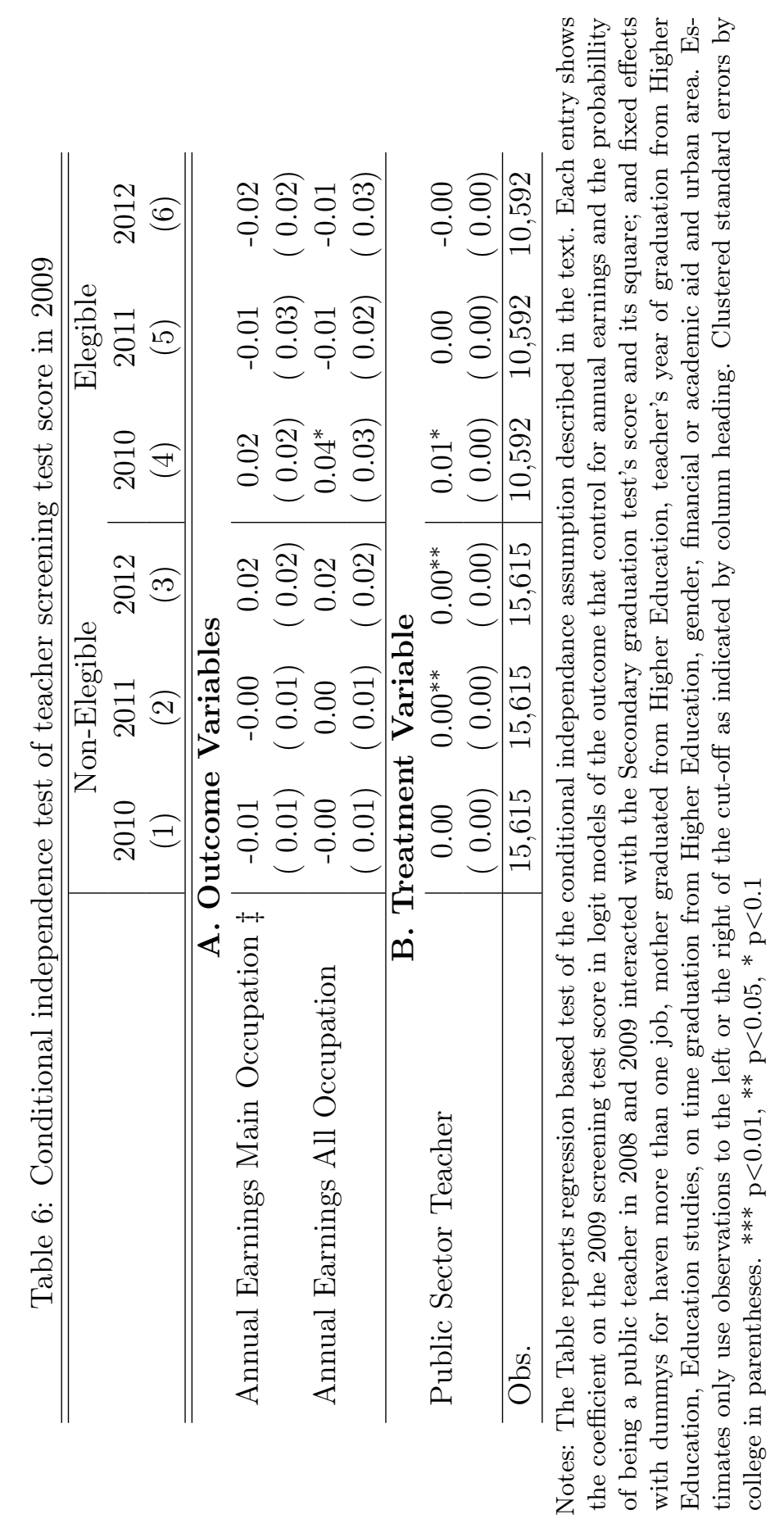




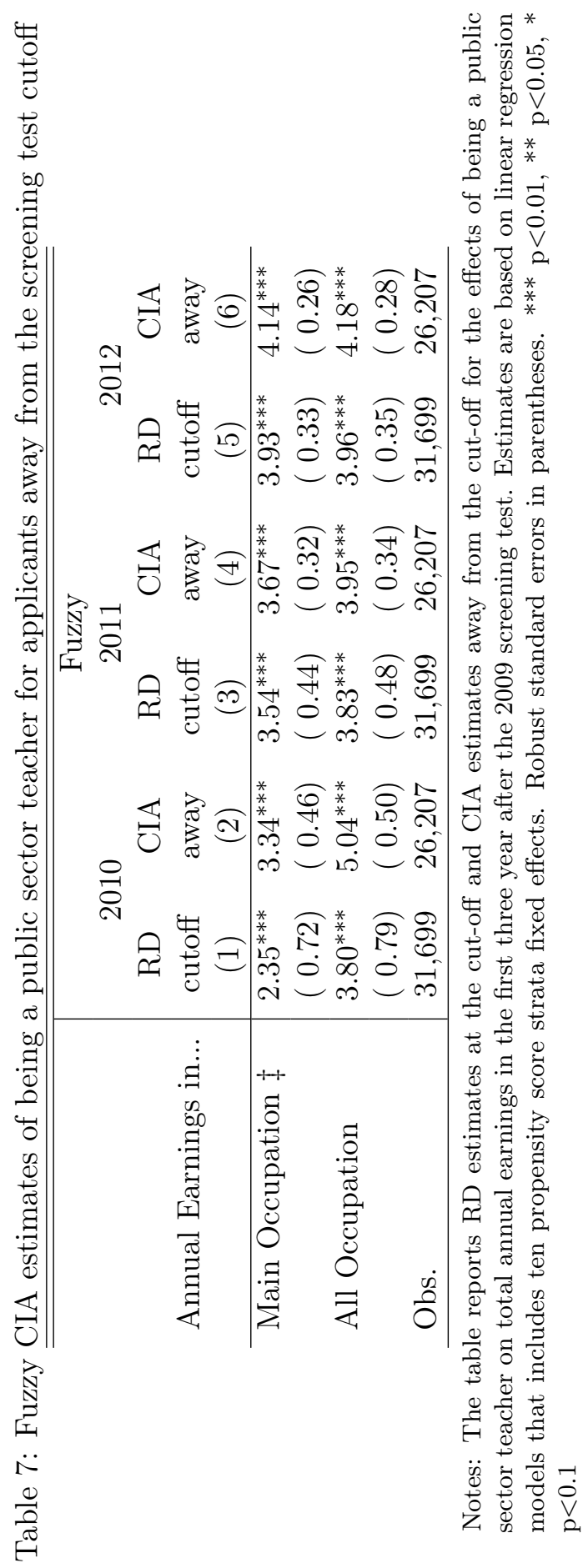




\section{A Data Appendix}

[Table A1 about here.]

[Table A2 about here.]

[Table A3 about here.]

[Table A4 about here.] 

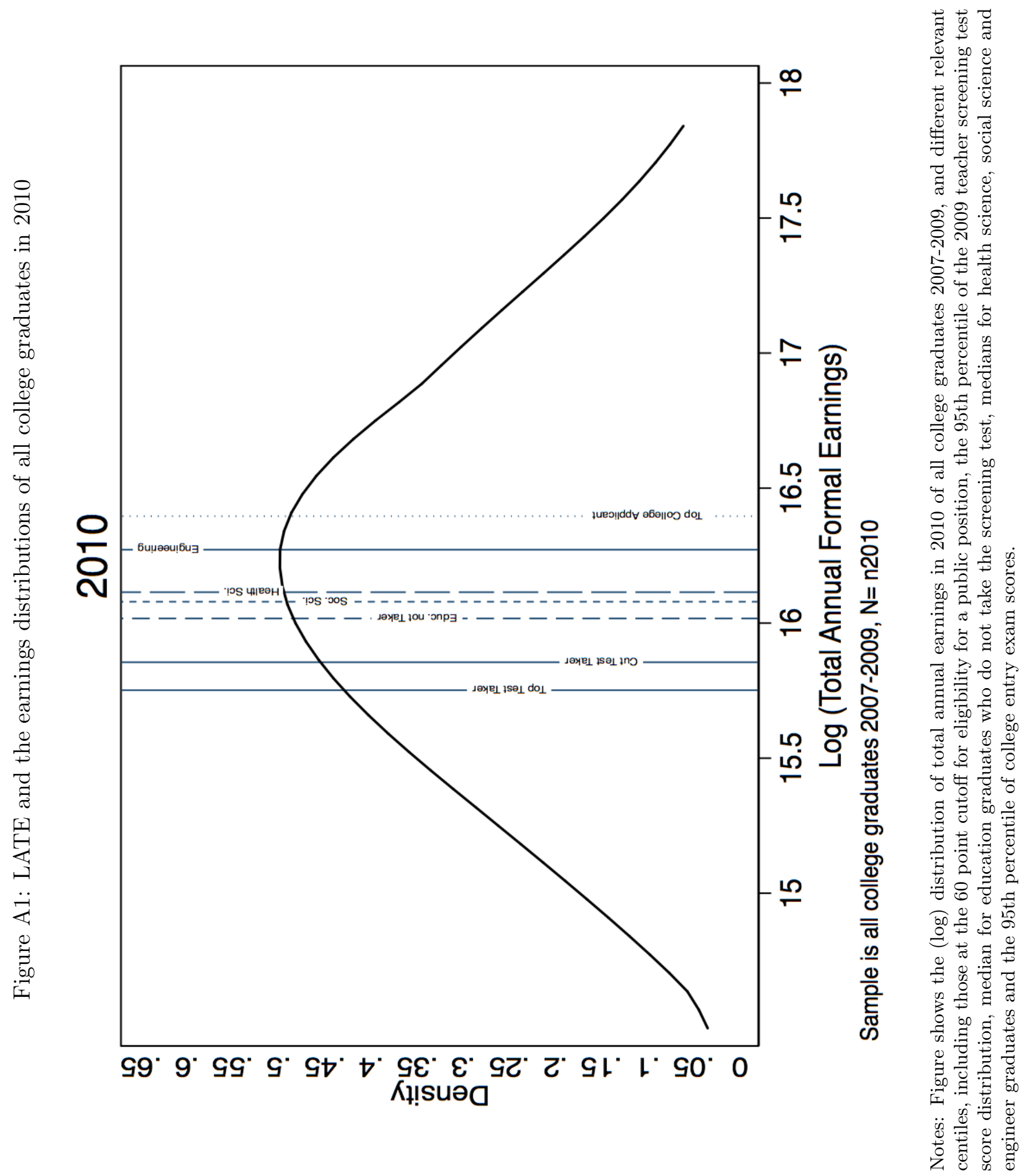


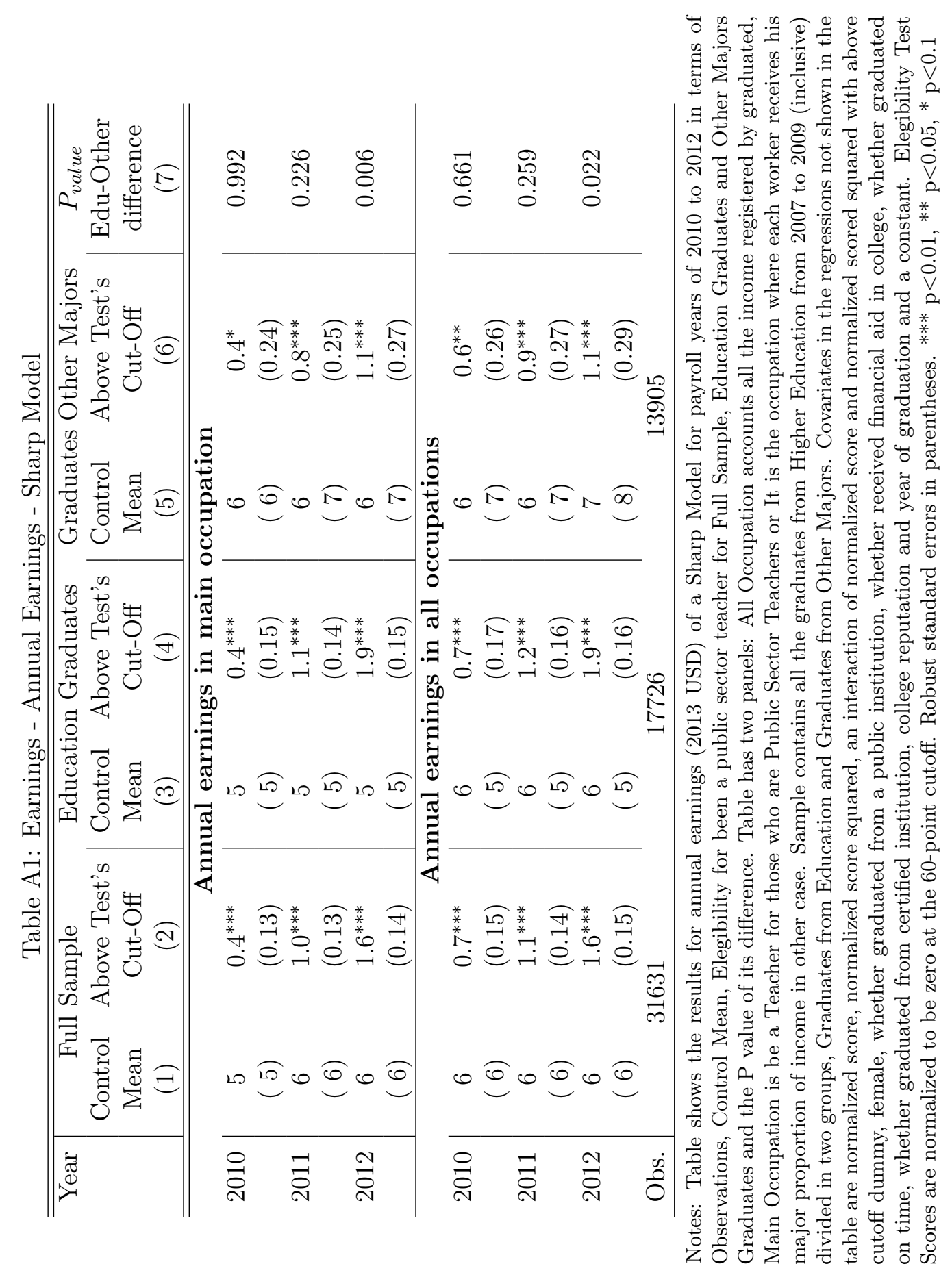




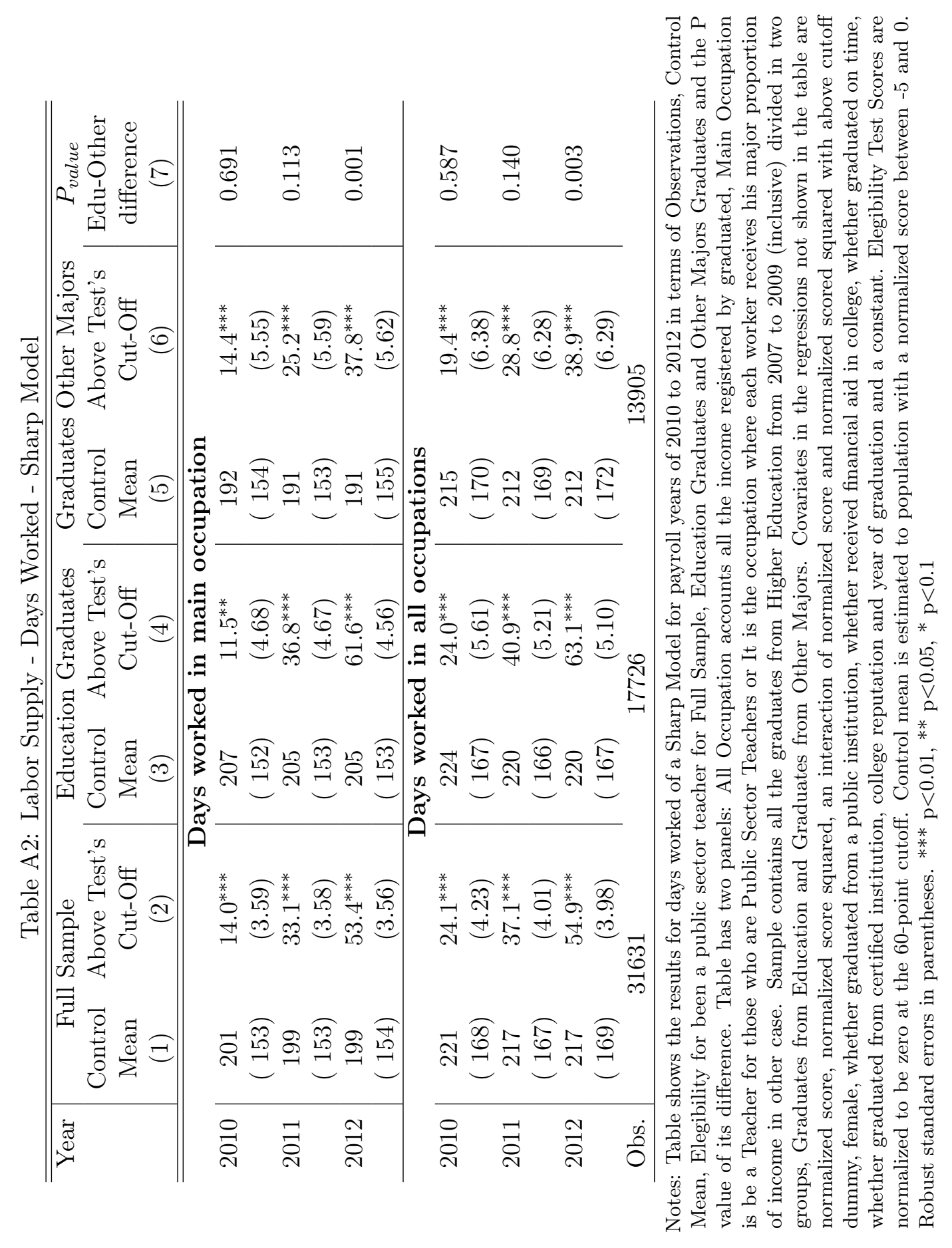




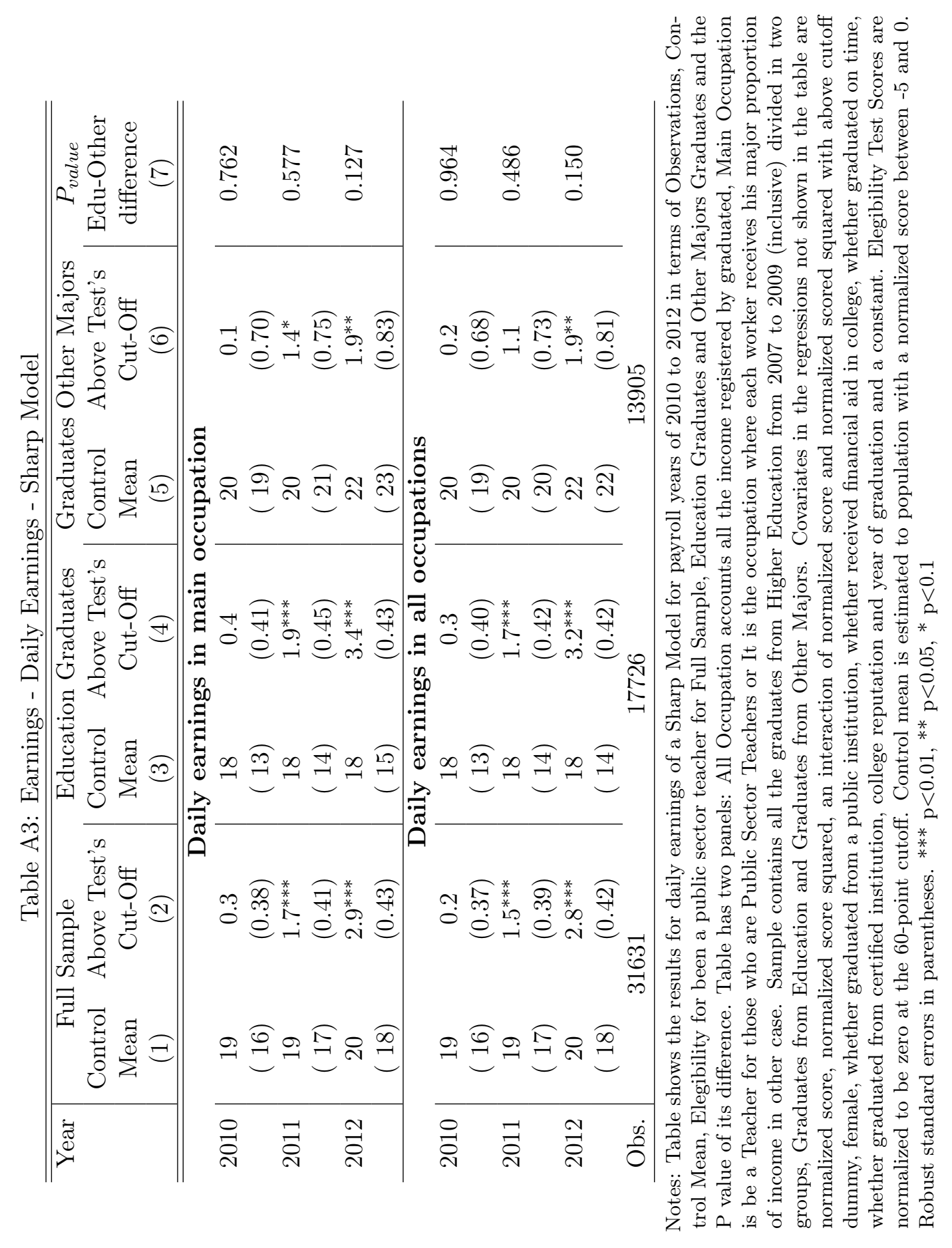




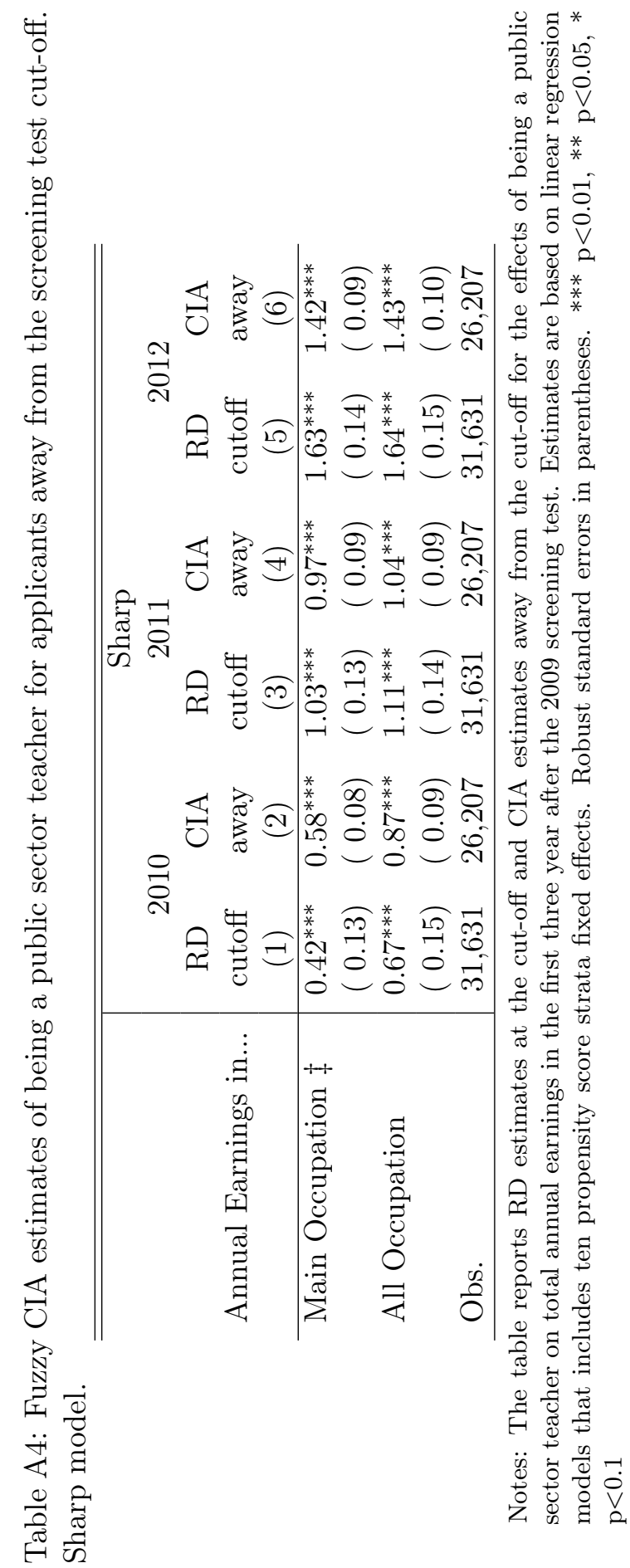

